\title{
Hydrothermal alteration of aragonitic biocarbonates: assessment of micro- and nanostructural dissolution-reprecipitation and constraints of diagenetic overprint from quantitative statistical grain-area analysis
}

\author{
Laura A. Casella ${ }^{1}$, Sixin $\mathrm{He}^{1}$, Erika Griesshaber ${ }^{1}$, Lourdes Fernández-Díaz ${ }^{2}$, Martina Greiner ${ }^{1}$, \\ Elizabeth M. Harper ${ }^{3}$, Daniel J. Jackson ${ }^{4}$, Andreas Ziegler ${ }^{5}$, Vasileios Mavromatis ${ }^{6}$, Martin Dietzel ${ }^{6}$, \\ Anton Eisenhauer ${ }^{7}$, Sabino Veintemillas-Verdaguer ${ }^{8}$, Uwe Brand ${ }^{9}$, and Wolfgang W. Schmahl ${ }^{1}$ \\ ${ }^{1}$ Department of Earth and Environmental Sciences and GeoBioCenter, Ludwig-Maximilians-Universität München, \\ Munich, 80333, Germany \\ ${ }^{2}$ Instituto de Geociencias, Universidad Complutense Madrid (UCM, CSIC), Madrid, 28040, Spain \\ ${ }^{3}$ Department of Earth Sciences, University of Cambridge, Cambridge, CB2 3EQ, UK \\ ${ }^{4}$ Department of Geobiology, Georg-August University of Göttingen, Göttingen, 37077, Germany \\ ${ }^{5}$ Central Facility for Electron Microscopy, University of Ulm, Ulm, 89081, Germany \\ ${ }^{6}$ Institute of Applied Geosciences, Graz University of Technology, Rechbauerstr. 12, 8010 Graz, Austria \\ ${ }^{7}$ GEOMAR-Helmholtz Centre for Ocean Research, Marine Biogeochemistry/Marine Geosystems, Kiel, 24148, Germany \\ ${ }^{8}$ Instituto de Ciencia de Materiales de Madrid (ICMM, CSIC), 28049 Madrid, Spain \\ ${ }^{9}$ Department of Earth Sciences, Brock University, 1812 Sir Isaac Brock Way, St. Catharines, Ontario, L2S 3A1, Canada
}

Correspondence: Laura A. Casella (laura.casella@lrz.uni-muenchen.de)

Received: 27 May 2018 - Discussion started: 10 July 2018

Revised: 8 November 2018 - Accepted: 16 November 2018 - Published: 21 December 2018

\begin{abstract}
The assessment of diagenetic overprint on microstructural and geochemical data gained from fossil archives is of fundamental importance for understanding palaeoenvironments. The correct reconstruction of past environmental dynamics is only possible when pristine skeletons are unequivocally distinguished from altered skeletal elements. Our previous studies show (i) that replacement of biogenic carbonate by inorganic calcite occurs via an interfacecoupled dissolution-reprecipitation mechanism. (ii) A comprehensive understanding of alteration of the biogenic skeleton is only given when structural changes are assessed on both, the micrometre as well as on the nanometre scale.

In the present contribution we investigate experimental hydrothermal alteration of six different modern biogenic carbonate materials to (i) assess their potential for withstanding diagenetic overprint and to (ii) find characteristics for the preservation of their microstructure in the fossil record. Experiments were performed at $175^{\circ} \mathrm{C}$ with a $100 \mathrm{mM} \mathrm{NaCl}+10 \mathrm{mMMgCl}_{2}$ alteration solution and lasted
\end{abstract}

for up to 35 days. For each type of microstructure we (i) examine the evolution of biogenic carbonate replacement by inorganic calcite, (ii) highlight different stages of inorganic carbonate formation, (iii) explore microstructural changes at different degrees of alteration, and (iv) perform a statistical evaluation of microstructural data to highlight changes in crystallite size between the pristine and the altered skeletons.

We find that alteration from biogenic aragonite to inorganic calcite proceeds along pathways where the fluid enters the material. It is fastest in hard tissues with an existing primary porosity and a biopolymer fabric within the skeleton that consists of a network of fibrils. The slowest alteration kinetics occurs when biogenic nacreous aragonite is replaced by inorganic calcite, irrespective of the mode of assembly of nacre tablets. For all investigated biogenic carbonates we distinguish the following intermediate stages of alteration: (i) decomposition of biopolymers and the associated formation of secondary porosity, (ii) homoepitactic overgrowth with preservation of the original phase leading to amalgama- 
tion of neighbouring mineral units (i.e. recrystallization by grain growth eliminating grain boundaries), (iii) deletion of the original microstructure, however, at first, under retention of the original mineralogical phase, and (iv) replacement of both, the pristine microstructure and original phase with the newly formed abiogenic product.

At the alteration front we find between newly formed calcite and reworked biogenic aragonite the formation of metastable $\mathrm{Mg}$-rich carbonates with a calcite-type structure and compositions ranging from dolomitic to about $80 \mathrm{~mol} \%$ magnesite. This high-Mg calcite seam shifts with the alteration front when the latter is displaced within the unaltered biogenic aragonite. For all investigated biocarbonate hard tissues we observe the destruction of the microstructure first, and, in a second step, the replacement of the original with the newly formed phase.

\section{Introduction}

Biomineralized hard parts composed of calcium carbonate form the basis of studies of past climate dynamics and environmental change. However, the greatest challenge that all biological archives face lies in their capacity to retain original signatures, as alteration of them starts immediately upon death of the organism (e.g. Patterson and Walter, 1994; Ku et al., 1999; Brand, 2004; Zazzo et al., 2004; Casella et al., 2018a, b).

Despite previous extensive research, carbonate diagenesis is still only partly understood (e.g. Bathurst, 1975; Brand and Veizer, 1980, 1981; Swart, 2015) as many studies addressing the evolution of parameters that influence diagenetic alteration, are discussed only in a qualitative manner (Brand and Veizer, 1980, 1981; Swart, 2015). In particular, deciphering the sequence of processes and, thus, pathways of alteration poses major problems in carbonate diagenesis (Immenhauser et al., 2015; Swart, 2015; Ullmann and Korte, 2015). Our previous study on the shell of the modern bivalve Arctica islandica has shown that laboratory-based, simulated diagenetic alteration discloses microstructural and geochemical features that are comparable to those found in fossil specimens (Casella et al., 2017; Ritter et al., 2017). However, the cited studies were performed on the hard tissue of only one taxon. For a more comprehensive understanding of microstructural and chemical controls at diagenesis we extend our studies to hard tissues of other modern marine carbonate biomineralizers such as the bivalve Mytilus edulis, the coral Porites sp., and the gastropod Haliotis ovina. With these we cover the major calcium carbonate phases, and with the inclusion of the shell of $A$. islandica, six distinct microstructures. When selecting organisms for this study, strict care was taken to investigate those taxa where fossil counterparts are often used for palaeoclimate and palaeoenvironmental reconstruction.
The bivalve $A$. islandica has been studied extensively in many scientific fields such as palaeontology, palaeoecology, biostratigraphy, and palaeoclimate research (e.g. Marchitto et al., 2000; Ridgway et al., 2011; Strahl et al., 2011; Wanamaker Jr. et al., 2011; Karney et al., 2012; Krause-Nehring et al., 2012; Butler et al., 2009, 2013; Schöne, 2013). The first occurrence of $A$. islandica in the Mediterranean Sea is of historical importance and was used until 2010 to mark the former Pliocene-Pleistocene boundary (e.g. Crippa and Raineri, 2015; Crippa et al., 2016). As long-lived organisms, stony corals attract great interest for the reconstruction of palaeoclimates derived from skeletal oxygen isotopic compositions and major element abundances, as these geochemical signals vary in response to changes in seawater temperature (e.g. Heiss, 1994; Cohen et al., 2001; McGregor and Gagan, 2002; Schöne et al., 2004, 2005a, b; Korte et al., 2005; Böhm et al., 2006; Allison et al., 2007; Meibom et al., 2007; Rüggeberg et al., 2008; Morton, 2011). For example, it is assumed that $\delta^{234} \mathrm{U}$ in sea water has remained constant in the past. Thus, the comparison between present-day and decaycorrected $\delta^{234} \mathrm{U}$ in sea water and in coral skeletons is a major tool for the detection of diagenetically altered corals. $\delta^{234} \mathrm{U}$ values of the latter are higher relative to present-day sea water (Hamelin et al., 1991; Stirling et al., 1995; Delanghe et al., 2002), while pristine corals exhibit a ${ }^{234} \mathrm{U} /{ }^{238} \mathrm{U}$ activity ratio similar to modern sea water (Henderson et al., 1993; Blanchon et al., 2009). Shells of molluscs (e.g. M. edulis), and gastropods (e.g. H. ovina) represent important archives for studies of palaeo- and present environmental change (Raffi, 1986; Richardson, 2001; Elliot et al., 2003; Wanamaker Jr. et al., 2008; Hippler et al., 2009; Schöne and Surge, 2012). The work of Hahn et al. $(2012,2014)$ has shown that environmental reconstruction can be derived from microstructural information, as well as stable isotope and major element data (Jackson et al., 1988; Cartwright and Checa, 2007; Gries et al., 2009).

In order to detect low to moderate degrees of alteration as well as to identify intermediate steps for the reconstruction of major pathways of overprint we investigated the behaviour of biocarbonate skeletal microstructure at laboratory-based hydrothermal overprint. We conducted alteration experiments for time spans between 1 and 35 days, at a temperature of $175^{\circ} \mathrm{C}$ and in the presence of a Mg-rich fluid. We investigated the skeletons of two modern bivalves (A. islandica and M. edulis), one modern stony coral (Porites sp.), and one modern gastropod (H. ovina). With this selection of hard tissue we are able to highlight the influence at alteration of variations in mineral surface area, control by primary (inherent) and secondary (induced) porosity, the effect of biopolymer fabric and pattern of distribution within the skeleton, and the impact of size, form, and mode of organization of biomineral units such as granules, fibres, tablets and prisms.

We discuss differences between biogenic to inorganic carbonate replacement kinetics, and illustrate differences in structure and porosity between original and overprinted prod- 
uct phases. Overprint strongly affects the size of mineral units in the alteration product, and we evaluate this characteristic for pristine and altered skeletons using statistical evaluation. Based on statistical grain-area analysis, we present a new and reliable tool for the detection of diagenetic overprint in biological carbonate hard tissues. This tool is sufficiently sensitive to characterize low degrees of diagenetic alteration.

\section{Materials and methods}

\subsection{Test materials}

Shells of the modern bivalve Arctica islandica were collected from Loch Etive, Scotland (UK). The shells are $8-10 \mathrm{~cm}$ in size and represent adult specimens. Pristine specimens of the scleractinian coral Porites sp. were collected at Mo'orea, French Polynesia (Rashid et al., 2014). Live specimens of the gastropod Haliotis ovina were collected from the reef flat of Heron Island, Queensland, Australia. All shell pieces used in this study were taken from the shell of one adult specimen with dimensions of approximately $8 \times 6.5 \mathrm{~cm}$. Shells of the modern common blue mussel, Mytilus edulis, were collected from 5-7 $\mathrm{m}$ depth in the subtidal zone of Menai Strait, Wales, UK. Shell sizes varied from 5 to $6 \mathrm{~cm}$ and represent adult animals.

\subsection{Methods applied}

\subsubsection{Selective etching of organic matrix}

In order to image the organic matrix in modern (reference) and hydrothermally altered shell samples, as well as the mineral reference (inorganic aragonite), shells or mineral pieces were mounted on $3 \mathrm{~mm}$ thick cylindrical aluminium rods using super glue. The samples were first cut using a Leica Ultracut ultramicrotome with glass knives to obtain planar surfaces. The cut pieces were then polished with a DIATOME diamond knife by stepwise removal of material in a series of 20 sections with successively decreasing thickness $(90,70$, $40,20,10$, and $5 \mathrm{~nm}$, and each step was repeated 15 times) as reported in Fabritius et al. (2005). The polished samples were etched for $180 \mathrm{~s}$ using $0.1 \mathrm{M}$ HEPES at a $\mathrm{pH}$ of 6.5 containing $2.5 \%$ glutaraldehyde as a fixation solution. The etching procedure was followed by dehydration in $100 \%$ isopropyl three times for $10 \mathrm{~min}$ each, before specimens were critical point-dried. The dried samples were rotary coated with $3 \mathrm{~nm}$ platinum and imaged using a Hitachi S5200 field-emission scanning electron microscope (FE-SEM) operating at $4 \mathrm{kV}$.

\subsubsection{Microstructure and texture}

For FE-SEM and electron backscatter diffraction (EBSD) analyses, $5 \times 5 \mathrm{~mm}$ thick pieces were cut out of the shells and embedded in epoxy resin. The surface of the embedded samples was subjected to several sequential mechan- ical grinding and polishing steps down to a grain size of $1 \mu \mathrm{m}$. The final step consisted of etch-polishing with colloidal alumina (particle size $\sim 0.06 \mu \mathrm{m}$ ) in a vibratory polisher. Samples were coated with 4-6 nm of carbon for EBSD analysis, and with $5 \mathrm{~nm} \mathrm{Pt} / \mathrm{Pd}$ for SEM visualization. EBSD measurements were carried out on a Hitachi SU5000 field emission SEM, equipped with an Oxford EBSD detector. The SEM was operated at $20 \mathrm{kV}$ and measurements were indexed with CHANNEL 5 HKL software (Schmidt and Olesen, 1989; Randle and Engler, 2000). Information obtained from EBSD measurements is presented as band contrast images, and colour-coded crystal orientation maps with corresponding pole figures.

The EBSD band contrast represents the signal strength of the EBSD-Kikuchi diffraction pattern and is displayed as a greyscale component of EBSD scanning maps. The strength of the EBSD signal is high when a crystal is detected (bright), whereas it is weak or absent when a polymer such as organic matter is scanned (dark/black). Co-orientation statistics are derived from pole figures obtained by EBSD scans and are given by the MUD (multiple of uniform (random) distribution) value. The MUD value measures crystal co-orientation (texture sharpness) in the scanned area, where a high MUD value indicates high and a low MUD value reflects a low to random co-orientation, respectively.

\subsubsection{Grain-area evaluation}

Individual grains can be identified and various grain related parameters, e.g. grain area, can be measured with EBSD. A grain is defined as a region completely surrounded by boundaries across which the misorientation angle relative to the neighbouring grains is larger than a critical value, i.e. the critical misorientation value. Griesshaber et al. (2013) empirically determined that a critical misorientation value of $2^{\circ}$ best suits the microstructure of modern carbonate biological hard tissues. By using this value, individual mineral units (e.g. fibres, tablets, prisms, columns), also called grains, can be addressed and evaluated. For the relative frequency to grainarea statistics, we use the critical misorientation value of $2^{\circ}$, grain clusters with a class width of $0.2 \mu \mathrm{m}$, and corrected values for absolute distribution function and probability density $(F x(x))$ to relative values. Care was taken that the quality of EBSD maps used in this study is very similar; hence all measurements were conducted with very small (200 to $300 \mathrm{~nm}$ ) step sizes. Measurements with a hit rate below $90 \%$ for calcite and below $70 \%$ for aragonite were not used for statistical evaluation.

\subsubsection{Alteration experiments}

Laboratory-based hydrothermal alteration experiments mimicked burial diagenetic conditions in terms of fluid composition. The latter is based on previously conducted hydrothermal experiments with a defined concentration of $\mathrm{Mg}$ that is 
comparable to $\mathrm{Mg}$ contents found in natural diagenetic environments. However, pressure conditions could not be adjusted to those of natural burial diagenesis due to the experimental design (closed system), and thus, corresponded to vapour pressure of water at the given temperature. In all experiments, pieces of shells or skeletons up to $2 \mathrm{~cm} \times 1 \mathrm{~cm}$ of modern A. islandica, modern M. edulis, modern Porites sp., and modern $H$. ovina were placed inside a polytetrafluoroethylene (PTFE) vessel together with $10 \mathrm{~mL}$ of simulated burial fluid ( $100 \mathrm{mM} \mathrm{NaCl}+10 \mathrm{mM} \mathrm{MgCl}_{2}$ aqueous solution) and sealed with a PTFE lid. Each PTFE vessel was placed in a stainless steel autoclave, sealed and kept in the oven at a temperature of $175^{\circ} \mathrm{C}$ for different periods of time ranging between 1 and 35 days. After the selected time period, the autoclave was removed from the oven, cooled down to room temperature and opened. Recovered solid material was dried at room temperature and prepared for XRD, EBSD, and EDX measurements.

\subsubsection{X-ray diffraction analysis}

X-ray diffraction analysis of pristine and hydrothermally altered samples was performed with $\mathrm{Cu}-\mathrm{K} \alpha_{1}$-radiation in reflection geometry on a General Electric Inspection Technologies XRD3003 X-ray diffractometer with an incident-beam Ge111 focussing monochromator and a Meteor positionsensitive detector (GE Inspection Technology GmbH). The diffractograms underwent Rietveld analysis with the software package FULLPROF (Rodríguez-Carvajal, 2001) using the aragonite structure data of Jarosch and Heger (1986) and calcite structure data of Markgraf and Reeder (1985).

\subsubsection{Thermal gravimetric analysis (TGA)}

Determination of organic matter content occurred via TGA measurements conducted in a TA Instruments Q500 TGA. The samples were heated from ambient temperature to $1000^{\circ} \mathrm{C}$ at a rate of $5^{\circ} \mathrm{C}$ per minute in a flowing-air atmosphere. The initial weight of samples used for TGA measurements was $20 \mathrm{mg}$ for A. islandica, $24 \mathrm{mg}$ for Porites sp., $26 \mathrm{mg}$ for H. ovina, $20 \mathrm{mg}$ for M. edulis nacre, and $22 \mathrm{mg}$ for M. edulis calcite.

\section{Results}

\subsection{Microstructural characteristics of modern bivalve, gastropod, and coral skeletons}

FE-SEM images shown in Figs. 1, A1, and A2 highlight characteristic mineral units and their assembly within the skeletons of the investigated species: the modern bivalves Arctica islandica and Mytilus edulis, the modern coral Porites sp., and the modern gastropod Haliotis ovina. Skeletons of A. islandica, H. ovina, and Porites sp. consist entirely of arago- nite, whereas M. edulis contains both carbonate phases, calcite and aragonite.

The shell of A. islandica comprises an assemblage of irregularly shaped, micrometre-sized aragonitic mineral units (white stars in Fig. 1a) that are interconnected by an irregular network of thin biopolymer fibrils (this study and Casella et al., 2017). Mineral unit size, porosity, and density of aragonite crystal packing is unevenly distributed within the shell, such that, relative to inner shell portions, mineral unit and pore sizes along the shell rim pointing to seawater are increased. Mineral unit organization in the shell of $A$. islandica is mainly unstructured, especially in shell portions along the seawater pointing shell rim. Despite this, aragonite that constitutes the inner shell layers, i.e. shell parts that are next to the soft tissue of the animal, is mainly present in a crossedlamellar microstructural arrangement. Growth lines in A. islandica shells are frequent and are easily observed, as in this species biopolymer contents and mineral unit sizes are increased (Casella et al., 2017; Greiner et al., 2018). Even though the shell of A. islandica can be addressed as consisting of densely packed aragonite, it contains primary porosity. The latter is unevenly distributed: along the seaward pointing shell portion, pores are abundant and large, while in shell parts that are closer to the soft tissue of the animal, pores are small and significantly less frequent (Greiner et al., 2018).

TGA measurements demonstrate that organic contents within the shell of pristine A. islandica are $2.2 \mathrm{wt} \%$ in the outer and $1.8 \mathrm{wt} \%$ in the inner shell portion, respectively. After 14 days of hydrothermal alteration we find $1.8 \mathrm{wt} \%$ in the outer and $1.7 \mathrm{wt} \%$ in the inner shell part, respectively. The skeleton of the modern stony coral Porites sp. consists of an assemblage of spherulitic units, the latter containing aragonitic needles and fibrils (white star in Fig. 1b). These grow radially outward from an organic template present at aragonite nucleation sites: the centres of calcification (white dots in Fig. 1b; Griesshaber et al., 2017). As skeletal growth proceeds, aragonite crystallites increase in size, and form thin fibres that are bundled into loosely co-oriented mineral units (framed in white and yellow in Fig. A1a; Griesshaber et al., 2017). When sectioned in two dimensions, spherical, irregularly shaped entities are obtained (yellow stars in Figs. A1b, c), which are cut-off from each other by cavities.

TGA measurements give $2.10 \mathrm{wt} \%$ organic material for the skeleton of modern stony coral Porites sp. When altered for 14 days the coral skeleton still contained $1.98 \mathrm{wt} \%$ of organic material. Hence, we find only a minor decrease in organic content with alteration for 14 days, at an alteration temperature of $175^{\circ} \mathrm{C}$ and in $\mathrm{Mg}$-rich burial fluid.

The shell of the modern gastropod $H$. ovina consists of aragonite. The latter is present in two microstructural arrangements (Figs. 1c, d, A2a): aragonite prisms and nacre tablets. Aragonite prisms (yellow stars in Figs. A2a, 1c) form the outer shell layer, while nacreous tablets (white stars in Figs. A2a, Fig. 1d) constitute inner shell portions. The prismatic mineral units in $H$. ovina show a gradation in size that 


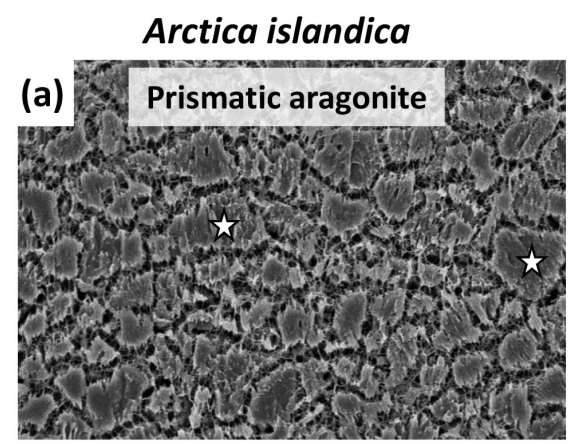

$5 \mu \mathrm{m}$

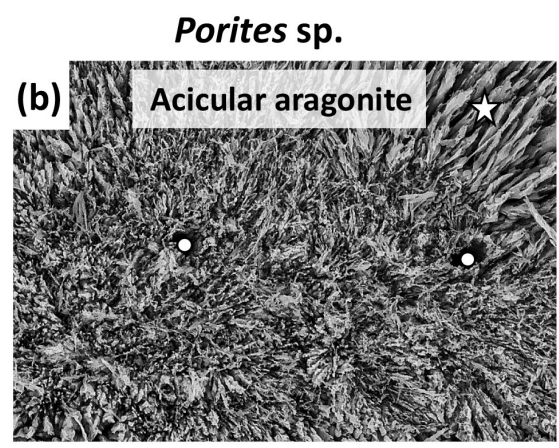

$5 \mu \mathrm{m}$

Haliotis ovina
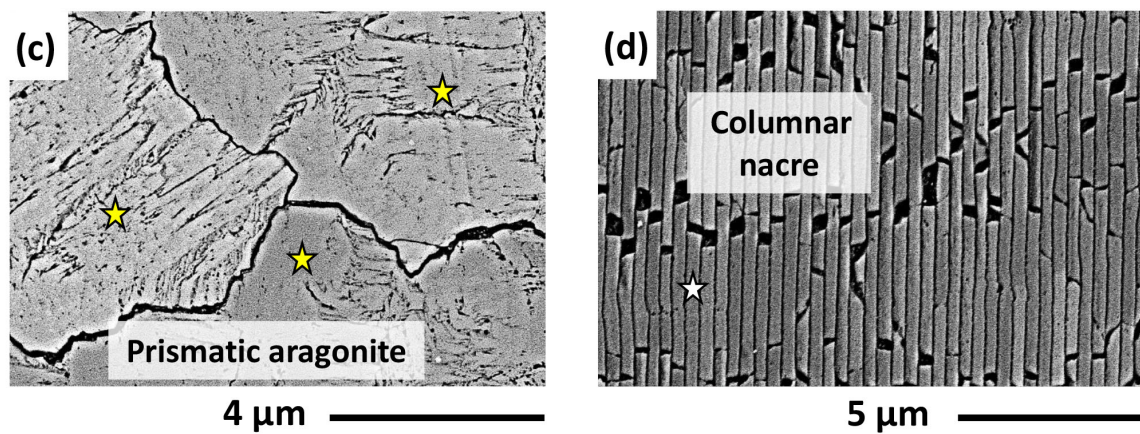

Mytilus edulis
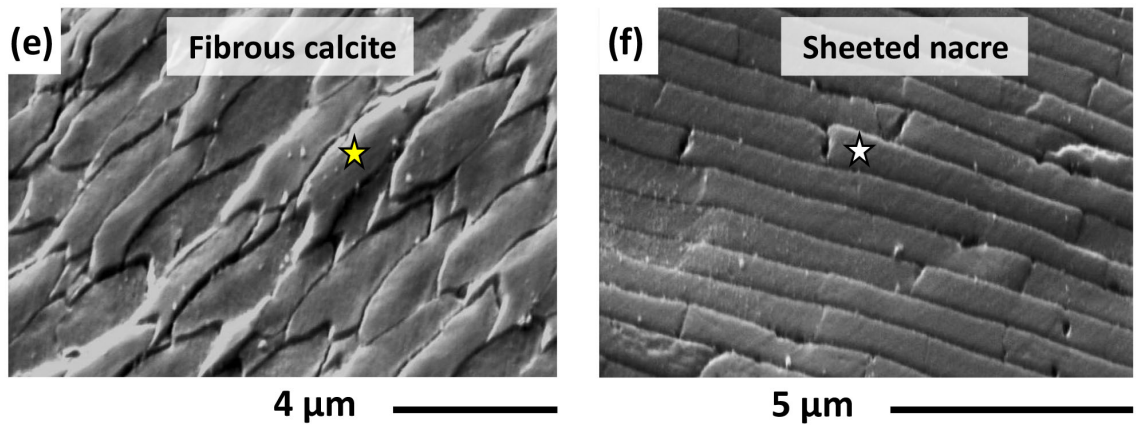

$5 \mu \mathrm{m}$

Figure 1. SEM micrographs showing the characteristic microstructures of skeletons of the modern specimens of (a) bivalve Arctica islandica, (b) scleractinian coral Porites sp., (c, d) gastropod Haliotis ovina, and (e, f) bivalve Mytilus edulis. The shell of A. islandica consists of an assemblage of irregularly shaped and sized aragonitic mineral units (white stars in a) which are embedded in a network of biopolymer fibrils (this study and Casella et al., 2017). The acicular aragonitic skeleton of the modern coral Porites sp. (white star in b) is composed of differently sized spherulites consisting of fibrils and needles. These grow outward from an organic template which lines the mineral nucleation sites, i.e the centres of calcification (white dots in b). Shells of the gastropod $H$. ovina and the bivalve $M$. edulis comprise two distinct carbonate layers. The shell of $H$. ovina consists of irregularly shaped and sized prisms (yellow stars in c) next to a nacreous shell layer with nacre tablets assembled as columns (white star in d). The outer shell layer in M. edulis is formed by stacks of calcite fibres (yellow star in e), while the inner shell layer is nacreous with nacre tablets arranged in a "brick wall fashion" (white star in $\mathbf{f}$ ).

decreases towards the rim of the outer shell. Accordingly, large aragonitic prisms are within the central part of the shell, next to nacreous aragonite. Nacreous tablets in $H$. ovina are stacked and form columns (white star in Fig. A2a).

TGA measurements give an organic content of $3.1 \mathrm{wt} \%$ for the shell of H. ovina. This value comprises both shell layers. The observed organic content agrees well with the over- all microstructural design of the shell of H. ovina. Most of the shell consists of dense nacreous aragonite, the latter being composed of thin ( 200 to $300 \mathrm{~nm}$ thick) tablets fully encased by a biopolymer sheath. The slightly porous prismatic aragonite shell layer forms only about $20 \%$ of the shell. At hydrothermal alteration for 21 days, the content of organics that is present in the shell of $H$. ovina decreased to $1.7 \mathrm{wt} \%$. 
The shell of the modern bivalve $M$. edulis contains arrays of highly co-oriented calcite fibres (yellow stars in Figs. 1e, A2b; Griesshaber et al., 2013; Checa et al., 2014) along the outward part of the shell. Inner shell layers consist of nacreous aragonite (white star in Figs. 1f, A2b). Aragonitic tablets in M. edulis are about $500 \mathrm{~nm}$ thick, are encased by an organic sheath, and are grouped in a sheeted, "brick-wall" arrangement (Fig. 1f; Griesshaber et al., 2013).

Organic contents are slightly different for the two shell layers, $2.7 \mathrm{wt} \%$ for the aragonitic and $2 \mathrm{wt} \%$ for the calcitic shell portion. Hydrothermal alteration for 21 days reduced the amount of organic material within the shell of $M$. edulis drastically to $0.7 \mathrm{wt} \%$ in the aragonitic and $0.6 \mathrm{wt} \%$ in the calcitic shell part, respectively.

\subsection{Microstructure and texture of hydrothermally altered bivalve, gastropod, and coral skeletons}

The shells and skeletal elements of modern Arctica islandica, Porites sp., Haliotis ovina and Mytilus edulis were subjected to laboratory-based hydrothermal alteration. Experiments were carried out at $175^{\circ} \mathrm{C}$ in the presence of a Mg-rich fluid simulating burial water. Experiments lasted between 1 and 35 days (Fig. A3).

The amount of newly formed calcite was determined by Rietveld analysis of XRD data (Fig. A4). Diagrams of calcite content vs. experimentation time (Fig. 2) demonstrate the difference in replacement kinetics between biogenic calcium carbonates and inorganic calcite, and highlight the profound influence of the biogenic microstructure on the replacement reactions. In hydrothermally altered $A$. islandica shells, new calcite formation starts after 4 days of alteration and progresses constantly. After 7 days of alteration, most shell aragonite is replaced by calcite (Figs. 2a, A4a; Casella et al., 2017). In contrast, the hard tissue of Porites sp. and of $H$. ovina respond differently to alteration. Replacement of biogenic aragonite by newly formed calcite is significantly slower compared to that occurring in the shell of $A$. islandica, such that after 35 days of alteration only $20 \%$ to $30 \%$ of biogenic aragonite is replaced by inorganic calcite (Figs. 2b, c, $\mathrm{A} 4 \mathrm{~b}, \mathrm{~d})$. For all five investigated types of microstructures, the amount of newly formed calcite is not a continuous function of time.

Microstructure and phase characterization was carried out with EBSD. The results are presented as EBSD band contrast (Figs. A5 to A8a), colour-coded orientation maps (Figs. 3 to 5, A8b), and corresponding pole figures (Figs. 3 to 5). EBSD band contrast is shown as a greyscale component that illustrates the strength of the diffracted signal for each measurement. Thus, when mineral material is hit by the electron beam, the backscattered signal is high and light grey colours form the image. When an organic component is scanned, the backscattered diffraction signal is absent, and the band contrast measurement image is black. Carbonate mineral coorientation strength is given with MUD values (e.g. Casella
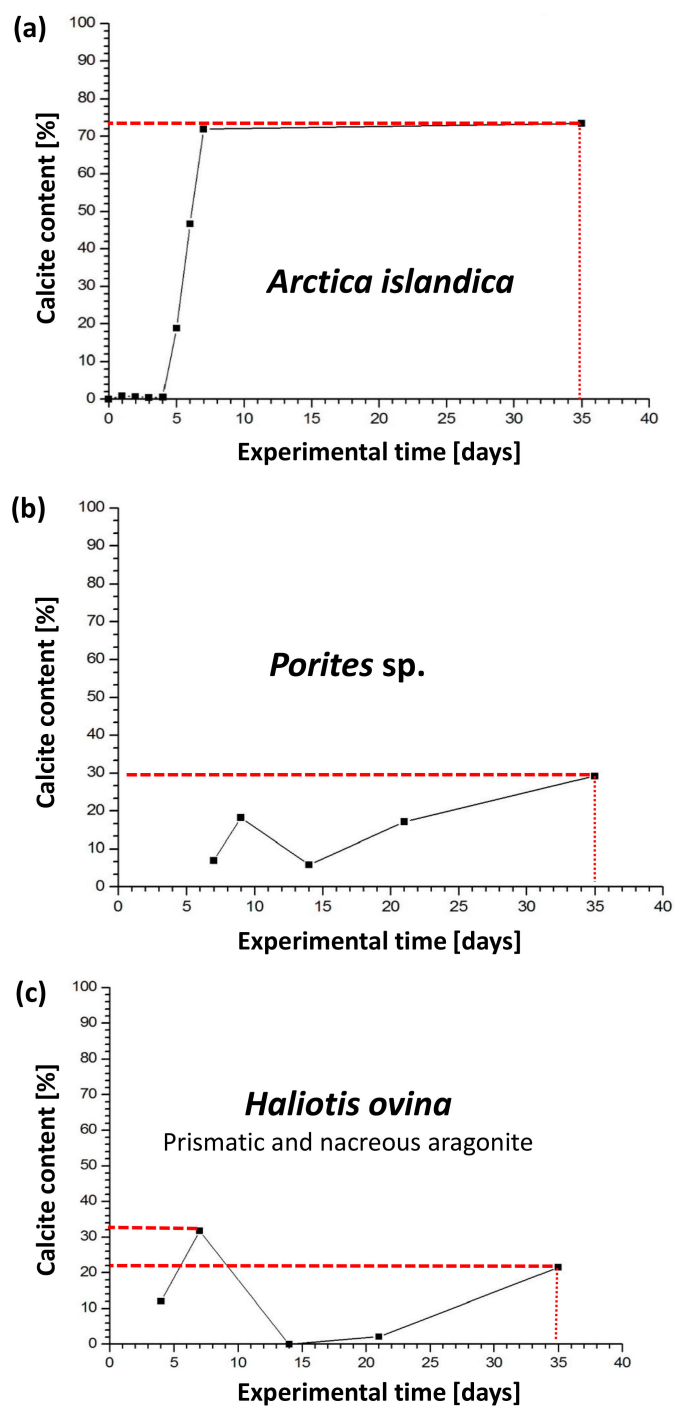

Figure 2. Newly formed inorganic calcite content vs. alteration time plots calculated from Rietveld analyses of XRD data obtained for hard tissues of (a) Arctica islandica, (b) Porites sp. and (c) Haliotis ovina. Red dashed lines indicate the percentage of newly formed calcite at 35 days of alteration as well as maximum contents of inorganic calcite for each investigated species. Differences in newly formed calcite contents among the three species clearly highlight the influence of the different microstructures on the replacement kinetics of biogenic carbonate by inorganic calcite.

et al., 2017, 2018a, b). These are derived from pole density distributions and are quoted for each EBSD scan.

Figures 3 to 5, and A5 to A8 show the difference in microstructure and texture between pristine samples and the most advanced stage of alteration (35 days, at $175^{\circ} \mathrm{C}$ in a Mg-rich fluid). At these conditions aragonitic mineral units in the shell of modern A. islandica (Fig. A5a) are quickly and almost completely replaced by inorganic calcite (Fig. A5b). In the modern shell these mineral units are surrounded by a 


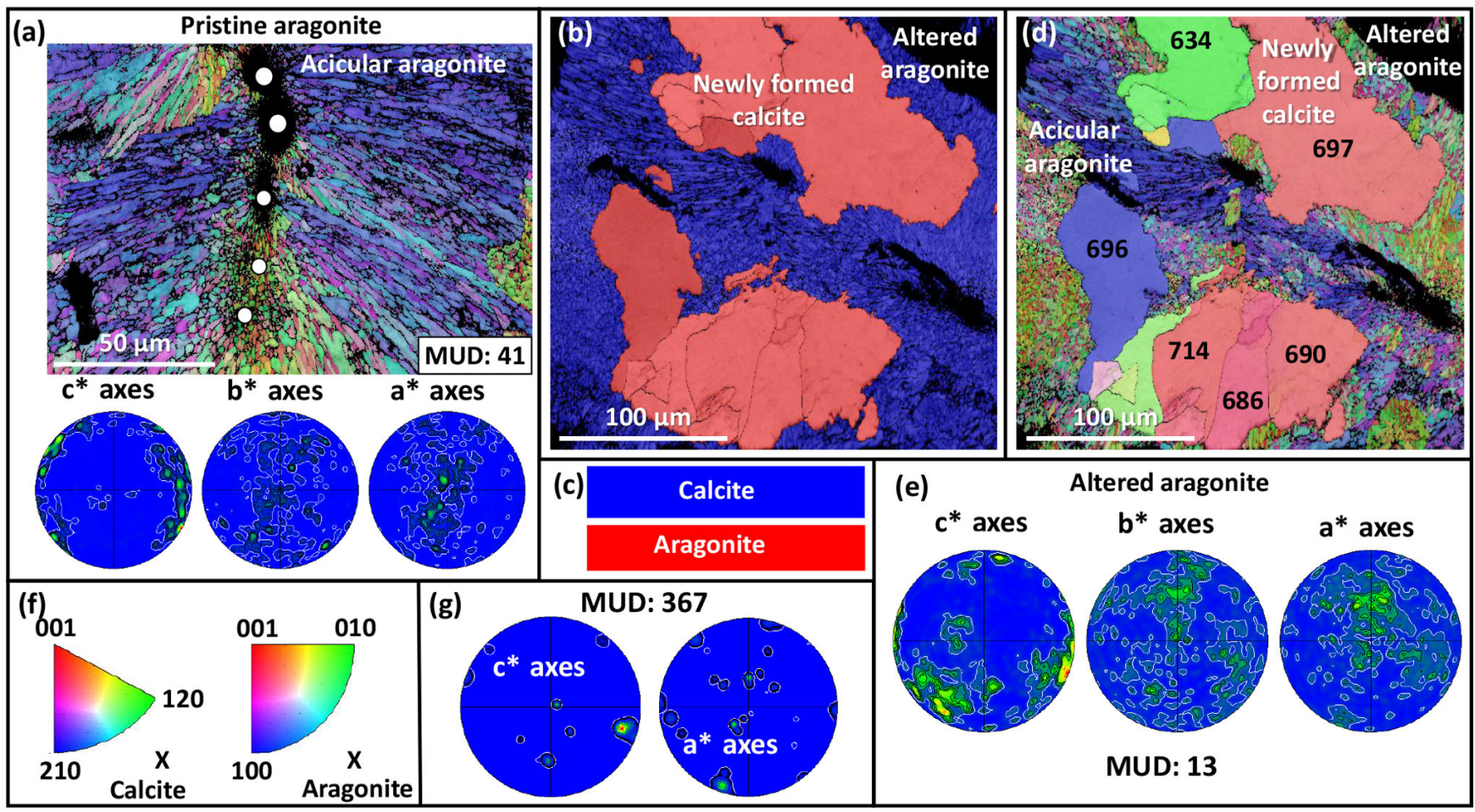

Figure 3. EBSD colour-coded orientation and phase maps with corresponding pole figures which depict the microstructure, texture and pattern of biogenic and inorganic carbonate phase distribution in pristine (a) and hydrothermally altered (b, c, d, e) skeletal elements of the scleractinian coral Porites sp. Alteration lasted for 35 days and was carried out at $175^{\circ} \mathrm{C}$ in a Mg-rich fluid simulating burial water $\left(100 \mathrm{mMNaCl}+10 \mathrm{mMMgCl}_{2}\right.$ aqueous solution). EBSD colour codes are given in (f). The strength of crystal co-orientation is expressed with MUD values and is given at each EBSD measurement. MUD values for newly formed calcites (d) are written into the EBSD map and are given for most newly formed calcite crystals. Even though crystal co-orientation strength is moderate in the modern coral specimen (MUD: 41 in a), it decreases significantly in the altered coral skeleton (MUD: 13 in d). Co-orientation strength in newly formed calcite is exceedingly high, as high as that of calcite grown from solution (d).

thin network of organic fibrils. The latter are easily destroyed at hydrothermal alteration and space is created for fluid percolation. Hence, a pervasive and quickly progressing replacement of biogenic aragonite by inorganic calcite takes place. Calcite nucleation and growth in A. islandica shells starts after a dormant period of about 4 days (Fig. A4a; Casella et al., 2017). Once started, the replacement progresses readily to completion. In the outer shell layer the replacement of aragonite is completed with the development of large and randomly oriented calcite grains, while, in denser shell areas, patches of biogenic aragonite are still preserved, containing features of the original biogenic microstructure and texture (see also Casella et al., 2017).

In contrast, acicular aragonite in Porites sp. displays a different behaviour during alteration. Even after alteration of 35 days only minor parts of the coral skeleton are replaced by calcite (Figs. 2b, $3 b$ to e, A5c, d). Our results show that the alteration fluid enters the coral skeleton predominantly at centres of calcification (Figs. 3b, d, A5d). New calcite formation starts mainly at these sites and proceeds from there into the skeleton. As Fig. 3d demonstrates, even after alter- ation for 35 days, at $175^{\circ} \mathrm{C}$ and in the presence of a $\mathrm{Mg}$ rich fluid, some regions of the acicular microstructure are still preserved. However, we see a decrease in MUD value from 41 in the pristine (Fig. 3a) to an MUD of 13 (Fig. 3e) in the altered shell. This is the only sign of alteration: the decrease in MUD indicates growth of new aragonite with a lower degree of crystallographic co-orientation of the newly formed mineral. With progressively longer alteration times, up to 35 days, large and randomly oriented calcite crystals grow within the coral skeleton (Figs. 3b, c, d, A5d). This calcite has high MUD values (Fig. 3d) similar to single crystalline calcite precipitated from solution (Nindiyasari et al., 2015; Casella et al., 2017).

Aragonite prisms in the pristine shell of H. ovina (Fig. 4a) are within a network of biopolymer fibrils which are readily destroyed by hydrothermal alteration. A significant amount of space becomes available for fluid infiltration, which results in extensive overprint and a rapidly progressing replacement of the biogenic aragonite by inorganic calcite. Figures $4 \mathrm{~b}$ and A6b show that after 35 days of alteration, in the presence of a Mg-rich fluid at $175^{\circ} \mathrm{C}$ the highly porous prismatic arago- 


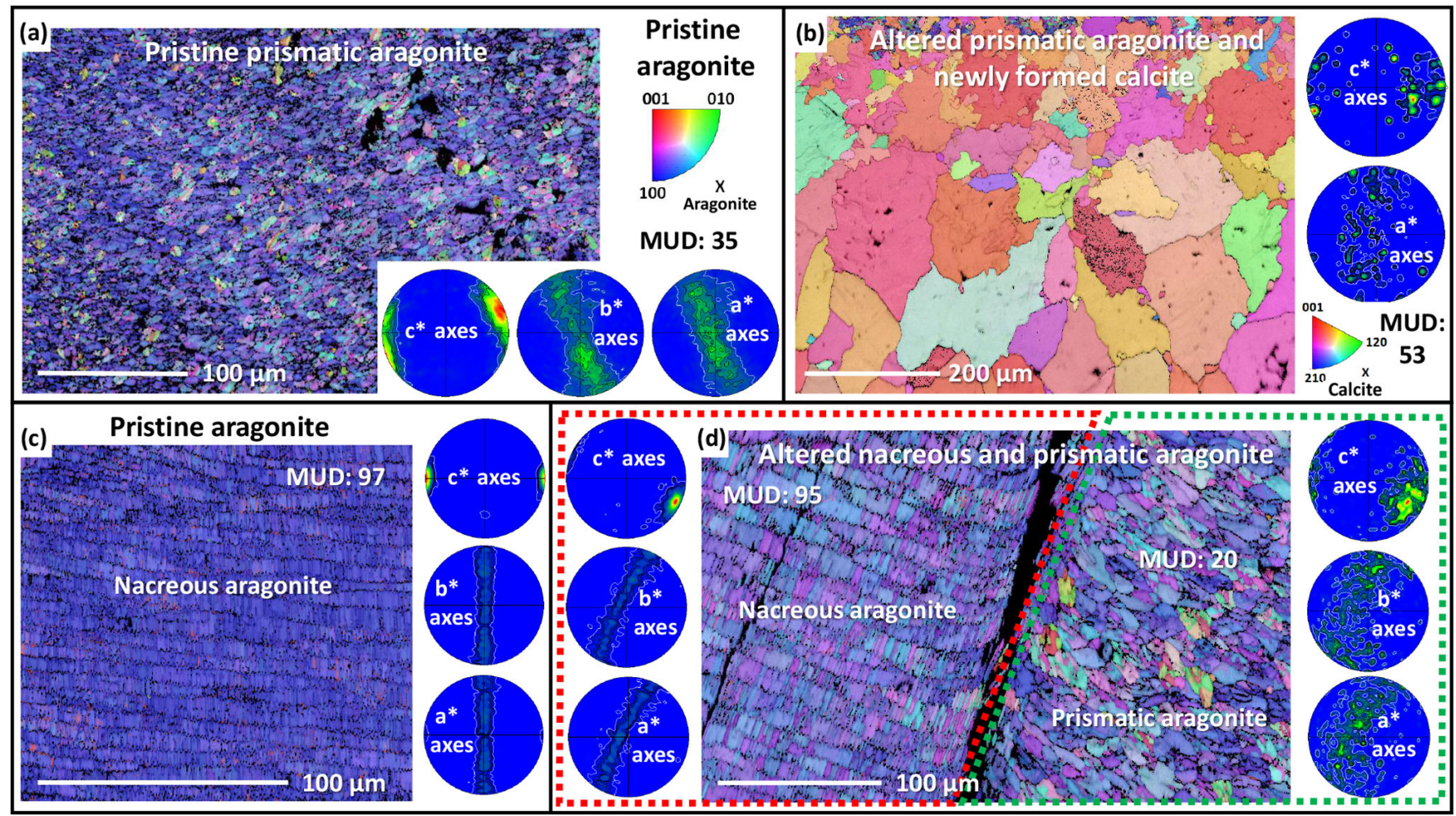

Figure 4. EBSD colour-coded orientation and phase maps with corresponding pole figures show the microstructure, texture, and pattern of biogenic and inorganic carbonate phase distribution in pristine (a, c) and hydrothermally altered (b, d) Haliotis ovina shells. Alteration lasted for 35 days and was carried out at $175^{\circ} \mathrm{C}$ in a Mg-rich solution. Crystal co-orientation strengths, expressed with MUD values, are given at each EBSD map. Alteration for 35 days induces the replacement of large parts of prismatic biogenic aragonite (a) by inorganic calcite (b). However, in shell layers where replacement has not yet taken place, aragonitic prisms amalgamate and MUD values decrease (right-hand side of EBSD map shown in (d) framed with a green dashed line; compare to EBSD map, pole figures, and MUD value shown in a). The nacreous part of the shell is little affected by alteration. Even when altered for 35 days the columnar microstructure is still well preserved (d). The MUD value of altered nacre (left-hand side of EBSD map shown in (d), framed in red) is very similar to that obtained for pristine nacre (c).

nite shell layer of modern H. ovina (Figs. 4a, A6a) is completely replaced by inorganic calcite. In contrast, the nacreous shell layer of $H$. ovina is little affected. There is no major change between pristine and altered $H$. ovina nacre, neither in carbonate phase, nor in microstructure or in MUD value (Figs. 4c, d and A6c, d).

Even though there is some correspondence in mineral unit morphology and size, and the extent of primary porosity and fabric of occluded biopolymers between prismatic aragonite in H. ovina and that in A. islandica, the kinetics of carbonate phase replacement is distinct for the two microstructures (Figs. 2a, c). In A. islandica, where small, irregularly shaped aragonite mineral units comprise the shell, replacement between carbonate phases is rapid and extensive, while replacement in the outer shell layer of $H$. ovina, where the shell consists of larger aragonite prisms, is slow and patchy. In addition, the difference between pristine and altered prismatic aragonite in $H$. ovina (compare pole figures and MUD values of Fig. 4a and d) is such that in the altered shell the size of aragonitic prisms increases while the strength of aragonite co-orientation decreases. This can be seen in the pole figures and the decreased MUD value (compare Fig. 4a with right hand part of Fig. 4d, the part framed in green).

In the pristine shell of $M$. edulis each calcite fibre is wrapped in an organic sheath. These decompose during alteration and leave space for fluid permeation and inorganic calcite reprecipitation. The comparison of Figs. 5a to c and Figs. A7a to $\mathrm{b}$ and $\mathrm{A} 8$ demonstrates that alteration of M. edulis calcite fibres at $175^{\circ} \mathrm{C}$, in the presence of a $\mathrm{Mg}$ rich fluid, results in severe distortion of the fibres. Crystal coorientation strength for fibrous calcite decreases markedly, from an MUD value of 381 in pristine to 79 in altered shell (Fig. 5a, c). In contrast to the calcitic fibrous microstructure, and similar to $H$. ovina nacre, after 35 days of alteration $\left(175^{\circ} \mathrm{C}\right.$, in the presence of a $\mathrm{Mg}$-rich fluid), there is no significant change between pristine and altered $M$. edulis aragonite nacre (Figs. 5b, d, A7c, d). In altered M. edulis amalgamation of nacre tablets can be observed (yellow stars in Fig. A7d), and a slight decrease in aragonite crystal coorientation strength (pristine nacre: MUD 129; altered nacre: MUD 105). 


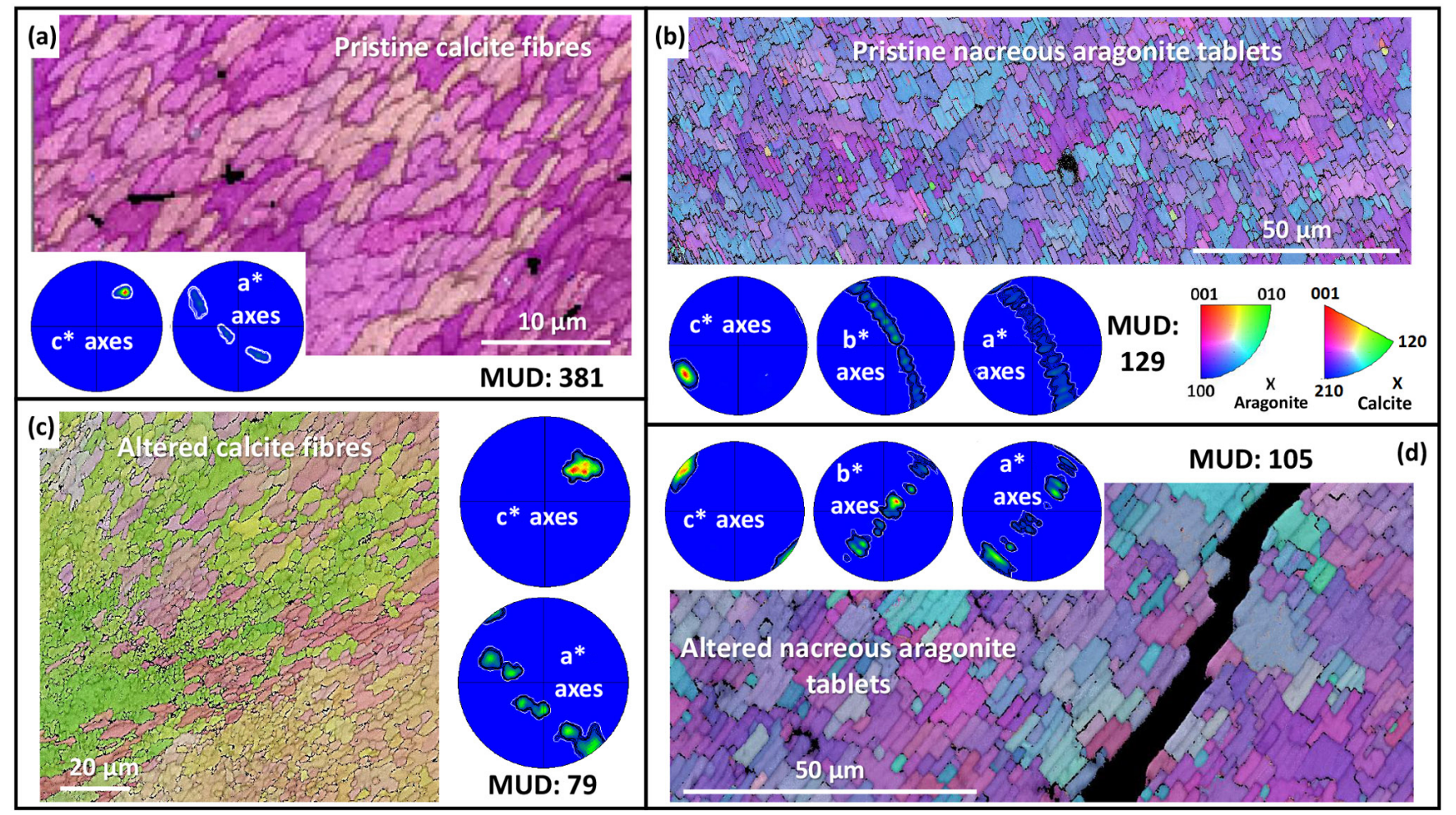

Figure 5. Colour-coded EBSD orientation maps with corresponding pole figures depict differences in microstructure and texture between pristine (a, b) and hydrothermally altered (c, d) Mytilus edulis shells. Alteration lasted for 35 days and was carried out at $175^{\circ} \mathrm{C}$ in a $\mathrm{Mg}$ rich fluid. The EBSD colour code used is shown in (b); crystal co-orientation strengths, expressed with MUD values, are given on each EBSD map. Hydrothermal alteration induces a significant change in pristine $M$. edulis calcite fibres (compare panels a and c). The strength of calcite co-orientation decreases from an MUD of 381 in the pristine (a) to a MUD of 79 in the altered shell (c), respectively. In the overprinted sample (c), morphology of calcite fibres is highly distorted due to profound fibre amalgamation. In contrast, nacre in $M$. edulis was little affected by the applied hydrothermal alteration conditions (d); a slight decrease in MUD and sporadic tablet amalgamation can be observed. Otherwise, tablet morphology is not distorted.

\subsection{Alteration pathways}

Major changes in microstructure which develop during different alteration times are depicted in Figs. A9 to A11. Subsequent to decomposition of organic material, for all investigated skeletons, we find that one of the first steps in the alteration process is an increase in mineral unit dimension relative to that in the pristine skeleton. In the Porites sp. coral skeleton, individual spherulites grow together (white stars in Fig. A9b, c) and form large and compact entities. Even though the alteration fluid accessed the skeleton from all sides, calcite formation in Porites sp. starts within the skeleton and proceeds outward toward the outer perimeter of the hard tissue (Fig. A9d). An increase in mineral grain size with progressive alteration can also be observed for both microstructures that constitute the shells of H. ovina (Fig. A10) and M. edulis (Fig. A11). As the organic sheaths around the mineral units decompose, space becomes available for new mineral formation. Aragonite prisms, calcite fibres, and nacreous tablets increase in size until they abut each other. In particular, the nacreous microstructure, irrespective of its specific arrangement into columns or sheets, and the calcite fibres form compact entities in response to alteration. In addition to an increase in fibre dimension, $M$. edulis calcite fibre morphology becomes highly distorted with progressive and long alteration duration. Even though the prisms of the prismatic shell layer in $H$. ovina also amalgamate, due to their slightly rounded and irregular morphology, voids become entrapped in this layer of the shell.

A further characteristic caused by hydrothermal alteration is the significant rise in porosity within individual mineral units (Fig. 6). Even though the latter grow together at their perimeters (Fig. 7) a multitude of nanopores develop within the mineral units due to decomposition of biopolymer fibrils that is present in mineral units of the pristine skeletons (e.g. Griesshaber et al., 2013; Casella et al., 2018a, b). However, as Fig. 8 shows, the inorganic calcite that forms from the altered biogenic aragonite is devoid of pores. The patches of pores that are visible within the newly formed calcite (white arrows in Fig. 8) are all residues of the incorporated altered biogenic prismatic aragonite. Our results indicate that major features of the mesoscale original microstructure are retained 


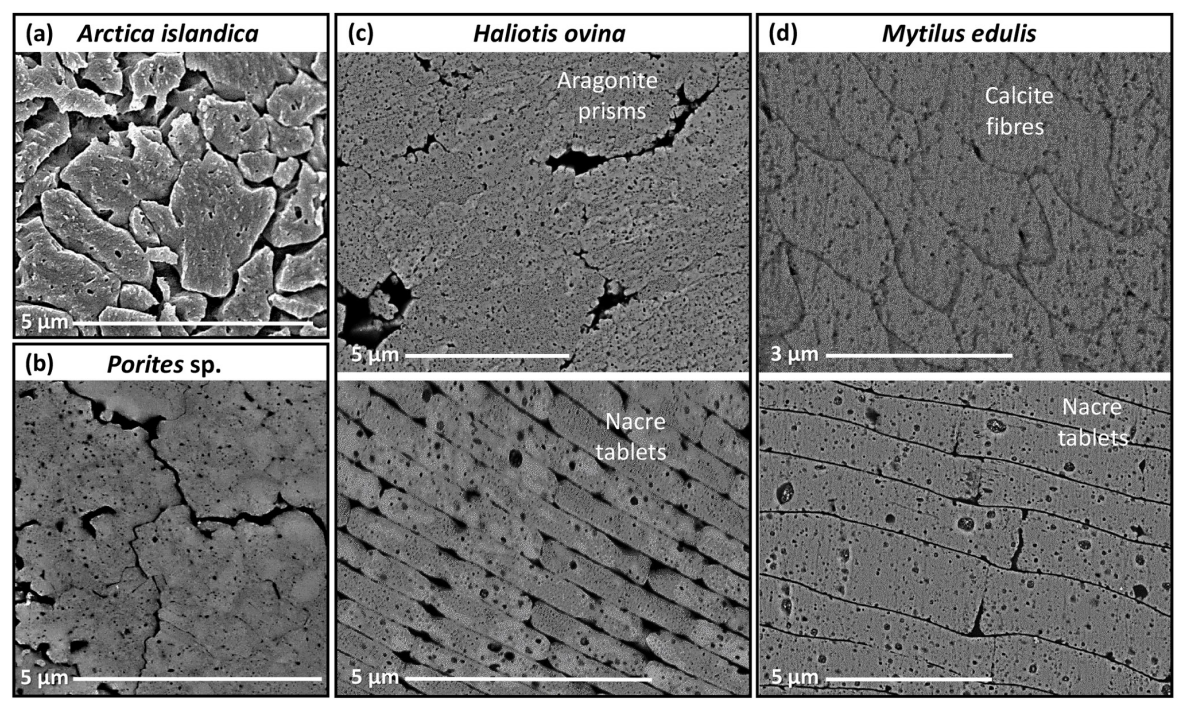

Figure 6. Distortion of mineral unit morphologies, mineral unit amalgamation, and development of porosity in hydrothermally altered shells and skeletons. (a) Arctica islandica, (b) Porites sp., (c) Haliotis ovina, and (d) Mytilus edulis. Hard tissue material was altered for 35 days at $175^{\circ} \mathrm{C}$ in the presence of a Mg-enriched fluid.
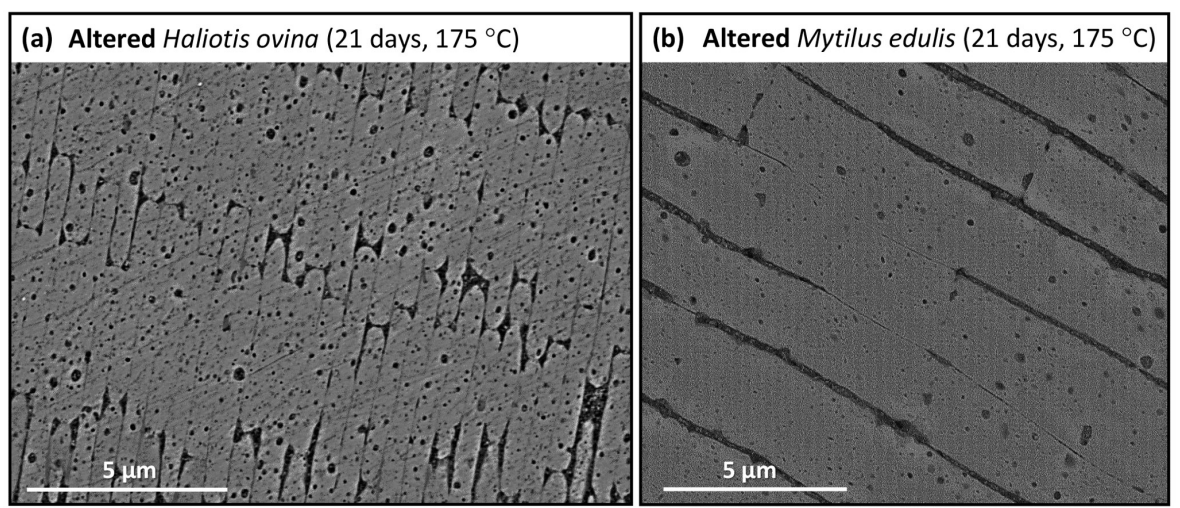

Figure 7. Nacre tablet amalgamation in hydrothermally altered Haliotis ovina (a), and in Mytilus edulis (b) shells. Hard tissue material was altered for 21 days at $175^{\circ} \mathrm{C}$ in the presence of an alteration fluid enriched in $\mathrm{Mg}$.

even at advanced stages of alteration (Fig. A12). In the shell of $H$. ovina, for instance, where prismatic aragonite is almost entirely replaced by calcite (Fig. A12), the original gradation in mineral unit size towards the rim of the outer shell layer is retained. Large newly formed calcite crystals (white stars in Fig. A12b) are within the central part of the shell next to nacreous aragonite and decrease in size towards outer shell portions (Fig. A12b) - as it is the case in the unaltered prismatic aragonitic shell.

Our results highlight that among all investigated microstructures, the nacreous microstructures are most resistant to hydrothermal alteration, irrespective of tablet thickness or their mode of organization (columns or sheets). We observed that replacement of biogenic nacreous aragonite by inorganic calcite takes place with the formation of various microstructural and chemical intermediate stages. These are described in detail for $H$. ovina nacre and are illustrated in Figs. 9-11 and A13-A15. Alteration of bivalve and gastropod nacre starts (i) with the decomposition of organic biopolymers between and within the tablets. This is followed by (ii) overgrowth with the original phase (aragonite) onto tablet rims and results in tablet amalgamation. Ongoing alteration (iii) destroys tablet assembly (blue stars in Fig. 9a, b) up to the complete obliteration of the nacreous microstructure (yellow stars in Figs. 9a, b, 10a, b). However, as the phase map in Fig. 9e shows, a phase replacement of biogenic aragonite by inorganic calcite does not take place at this stage of overprint. Our results show that the microstructure is destroyed first; replacement of one carbonate phase by another occurs subsequently (Fig. 9). During alteration in a Mg-rich fluid, a Mg-rich seam of calcite is always present at the phase replacement front, between the newly formed calcite and 


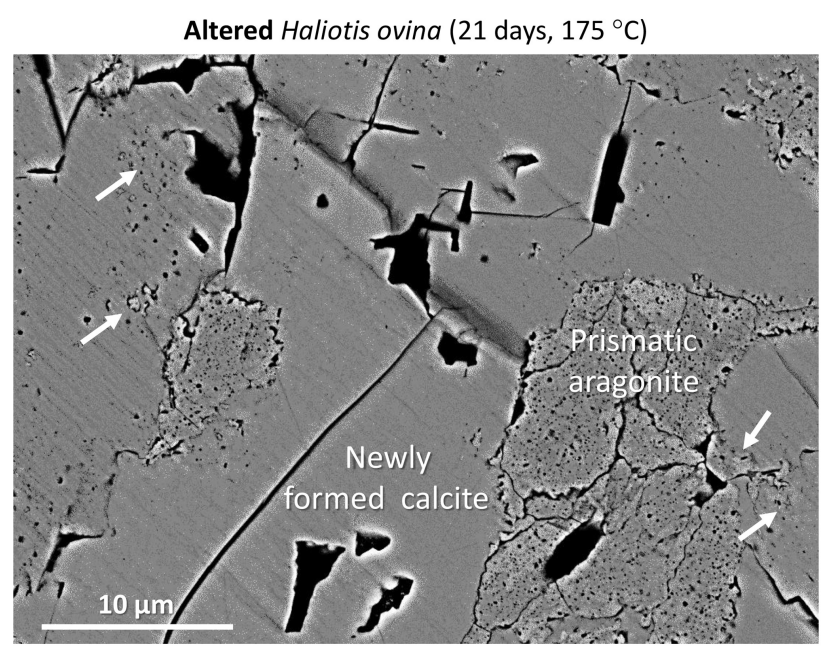

Figure 8. Distinctness in porosity between hydrothermally altered biogenic prismatic aragonite and newly formed inorganic calcite. White arrows point to the aragonite interspersed with calcite; the aragonite is not yet fully consumed and replaced by calcite.

the highly overprinted nacreous aragonite (white arrows in Figs. 9a, d, A14, white arrows in Fig. A15a). Based on differences in Mg-contents, we find different metastable $\mathrm{Mg}$-rich carbonates with a calcite-type structure and compositions from dolomitic to ca. 80 mole \% magnesite (Figs. 10, 11, A15). These segregate between the "final" low-Mg calcite and the overprinted (reworked) aragonite (Figs. 11, A15). The last step in the replacement of biogenic nacreous aragonite by inorganic calcite is (iv) the formation of low-Mg calcite (the final calcite), which in the final stage of alteration constitutes the overprinted hard tissue. We could often observe that despite the change from one carbonate phase into another, the newly formed calcite retains much of the original mesoscale morphology of the mineral units inherited from the pristine biogenic skeleton.

\section{Discussion}

Biomineralized tissue provides the bulk of fossil material that is used for geochemical analysis. As all fossil archives are overprinted to some degree, it is of major importance to identify those that are subject to minor and moderate degrees of overprint, as (i) these are the materials that contain most primary information, and (ii) identification of extensive overprint is not challenging, as a severely overprinted microstructure is either highly distorted or is completely destroyed. The latter two characteristics are easily identified, while microstructures with a low to moderate degree of overprint are difficult to recognize and to detect.

Accordingly, important questions that arise in this context are as follows: what are the intermediate steps of diagenetic alteration? What is modified first, easily destroyed and/or keeps for a short time only? The original skeletal microstructure, the original mineralogical phase, the geochemical information? What happens to the original geochemical information that is stored within the biogenic archive? On a broader scale, can we identify major pathways of diagenetic overprint? What determines the preservation potential of a fossil archive?

\subsection{The process of overprint}

Diagenetic overprinting of biogenic carbonates encompasses morphological and chemical changes that take place during post-mortem alteration. Fluids act as catalysts for the alteration reactions at fluid-rock contacts and allow the overprint reactions to proceed at a rapid rate (Brand, 1994). This response is in contrast to solid-state alteration in dry systems, where overprint kinetics is much slower. Brown et al. (1962) have shown that replacement of aragonite by calcite at Earth surface pressure and temperature conditions is 10 orders of magnitude faster in the presence of water compared to dry conditions. Accordingly, with the death of the organism and burial in sediments, biomineralized hard tissues become subject to diagenetic overprint, to solvent-mediated phase replacement (Cardew and Davey, 1985), or the coupled dissolution of the original material and the reprecipitation of the new product(s) (Putnis, 2002, 2009).

It has been shown for inorganic systems that coupled dissolution-reprecipitation is highly influenced by the availability of interfaces, the reactivity of surfaces, and the extent and topological characteristics of the original and newly formed porosity (Putnis, 2002, 2009; Arvidson and Morse, 2014; Ruíz-Agudo et al., 2014). It is demonstrated that coupling of the two (sub)reactions takes place when the rate of dissolution of the original phase and the rate of crystallization of the product is almost equal. This has the effect that coupled dissolution-reprecipitation of mineral replacement proceeds with preservation of the external shape of the primary mineral, and leads to formation of pseudomorphs (Xia et al., 2009a; Qian et al., 2010). Is the coupling between dissolution and recrystallization well balanced, delicate microtextural features are well preserved, e.g. twin boundaries (Xia et al., 2009b) or even small features such as exsolution lamellae (Altree-Williams et al., 2015).

In inorganic materials microstructural elements such as grain boundaries are of key importance for the progress of the overprint process as at the first stages of alteration, these provide the pathways for fluid infiltration and percolation through the material (Etschmann et al., 2014; Jonas et al., 2014). In inorganic systems, mass transfer along grain boundaries is an order of magnitude faster than through the porosity which forms as a result of the mineral replacement reaction (Etschmann et al., 2014; Jonas et al., 2015). However, with progressive alteration an interconnected pore system develops in inorganic materials (Putnis, 2002, 2009; Pollok et al., 2011; Ruíz-Agudo et al., 2014; Altree-Williams et 

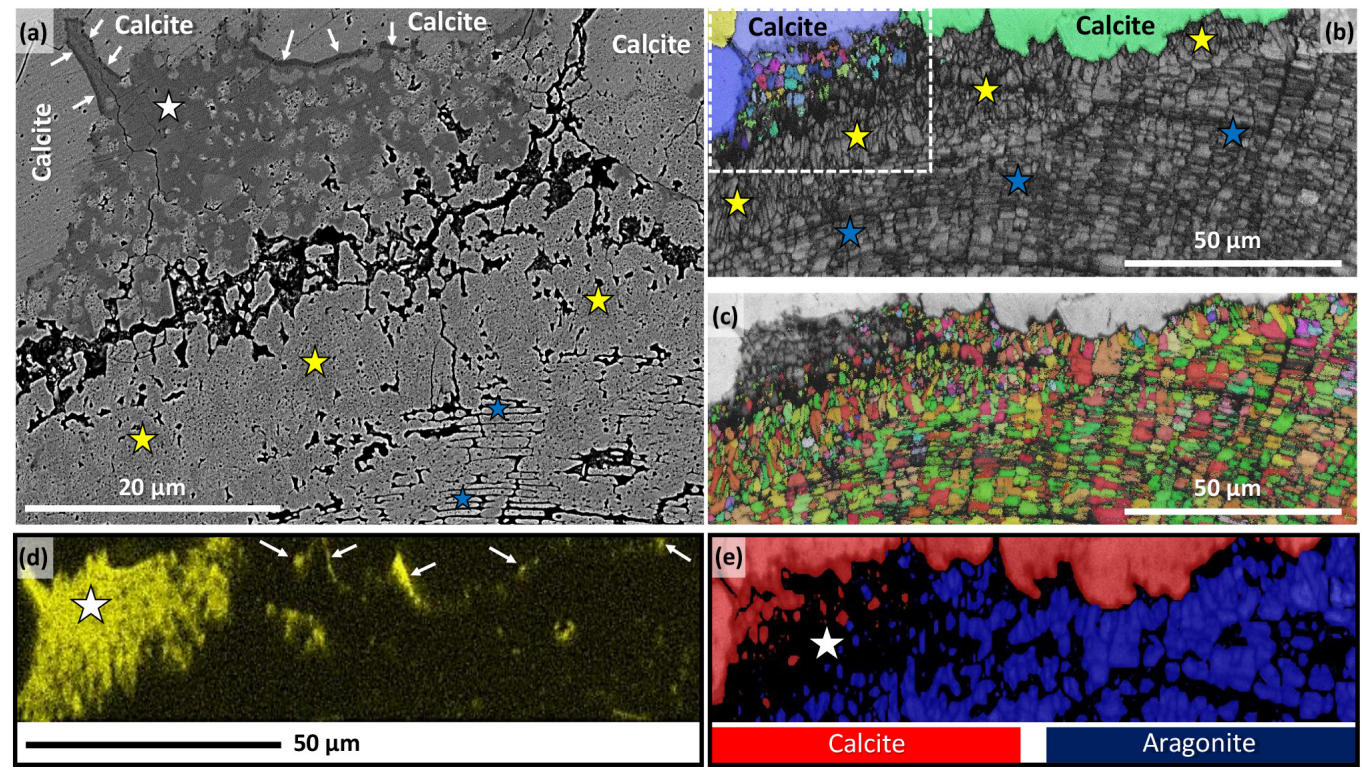

Figure 9. Microstructural and chemical stages in the replacement process of biogenic nacreous aragonite by inorganic calcite. Haliotis ovina shell material was subjected to hydrothermal alteration for 35 days at $175^{\circ} \mathrm{C}$ in a Mg-enriched hydrothermal fluid. (a) SEM image depicting the replacement front between nacreous aragonite and newly formed calcite. Blue stars in (a): nacre tablets forming columns; some traces of the original microstructure can be still observed. Yellow stars in (a): a formerly nacreous shell layer, but, at this stage of alteration, the nacreous microstructure is completely erased. White arrows, white star in (a): high-Mg intercalation between the newly formed calcite and the overprinted, formerly biogenic, aragonite (yellow stars in a). (e) Phase map derived from EBSD showing the newly formed calcite (red) and biogenic aragonite (blue). Note that even though the tablet microstructure cannot be discerned any more, the original mineralogical phase (aragonite) is still preserved. The white star in (e) marks the region where high-Mg calcite intercalation is located, which, in the presence of a Mg-rich fluid, is always present at the replacement front between inorganic calcite and biogenic aragonite. (d) EDX map showing the enrichment in $\mathrm{Mg}$ at the transition front in yellow. (b, c) EBSD band contrast shown in grey, and colour-coded orientation maps, respectively depicting traces of columnar aragonite (blue stars in b) and overprinted aragonite (yellow stars in b). Coloured in (b): newly formed calcite. Shell layer which is marked with a white dashed rectangle in (b) is shown enlarged in (a). (c) Colour-coded EBSD map of aragonite; in light grey: newly formed calcite, in dark grey: rim containing high-Mg calcite.

al., 2015) and allows (in ideal cases) for continuous communication between the bulk aqueous phase and the primary and secondary phases at the reaction front (Putnis, 2002, 2009; Etschmann et al., 2014). Besides, pore formation also develops as a direct consequence of the mineral replacement process, in those cases where the molar volume change involved in the reaction is negative. A further source of porosity development during mineral replacement relates to the difference in solubility between the primary and secondary phases (Pollok et al., 2011). Porosity is generated when the primary phase is more soluble than the secondary phase, as a small amount of the latter precipitates after dissolution of the former. In the case of the investigated biogenic carbonates, even though the solubility of biogenic aragonite is higher than the solubility of inorganic calcite, the solubility difference is not large enough to compensate the positive volume change in the dissolution-reprecipitation reaction. A positive molar volume change of only $8.12 \%$ is associated with the replacement of aragonite by calcite (Perdikouri et al., 2011, 2013).
Perdikouri et al. (2011) investigated the replacement of inorganic aragonite by inorganic calcite. The authors immersed inorganic aragonite in pure water and in solutions which contained calcium and carbonate, with the solutions being saturated with respect to calcite but undersaturated with respect to aragonite. In experiments which were carried out in the presence of water, a replacement was not observable, even after an entire month, unless the solution temperature was equal or higher than $180^{\circ} \mathrm{C}$. However, even at elevated temperatures there was only a narrow rim of aragonite replaced by some calcite overgrowth. The newly formed calcite was devoid of pores; hence, there was no communication between the bulk aqueous phase and the phases at the reaction front. It sealed the aragonite and prevented further progressive replacement.

By using aqueous solutions containing calcium and carbonate Perdikouri et al. (2011) obtained different results. When the composition of the solution was stoichiometric, comparable results were obtained to the experiment with water: little replacement of the original material and the formation of a non-porous calcite overgrowth. In contrast, at al- 

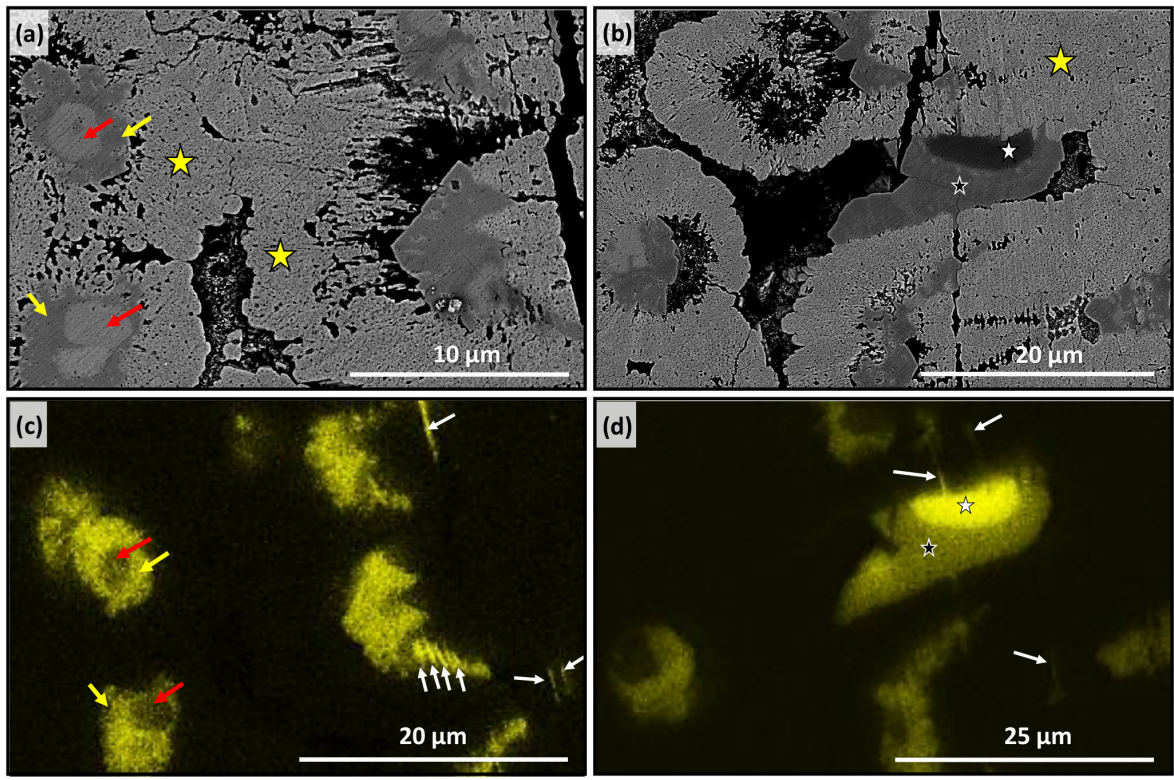

Figure 10. Replacement of biogenic aragonitic nacre by inorganic calcite. (a) SEM image showing the nucleation and growth of inorganic calcite within shell aragonite. Note the residual aragonite (red arrows in a and c) replacing calcite crystals (yellow arrows in a and c). Yellow stars in (a): faint traces of nacre columns. (b) SEM image depicting the formation of high-Mg calcite crystals (white stars) within the overprinted, originally nacreous shell layer (yellow star in b). Tablet assemblages of columns (yellow star in b) are still perceivable. (c, d) EDX map showing (yellow) the presence of calcite crystals with high-Mg content (white and yellow arrows in c, stars and white arrows in d). Red arrows in (c): traces of occluded aragonite distinguished by a low Mg content. White arrows in (c, d): high-Mg streaks that form in cavities between nacreous tablets subsequent to the decomposition of biopolymer membranes around the tablets.
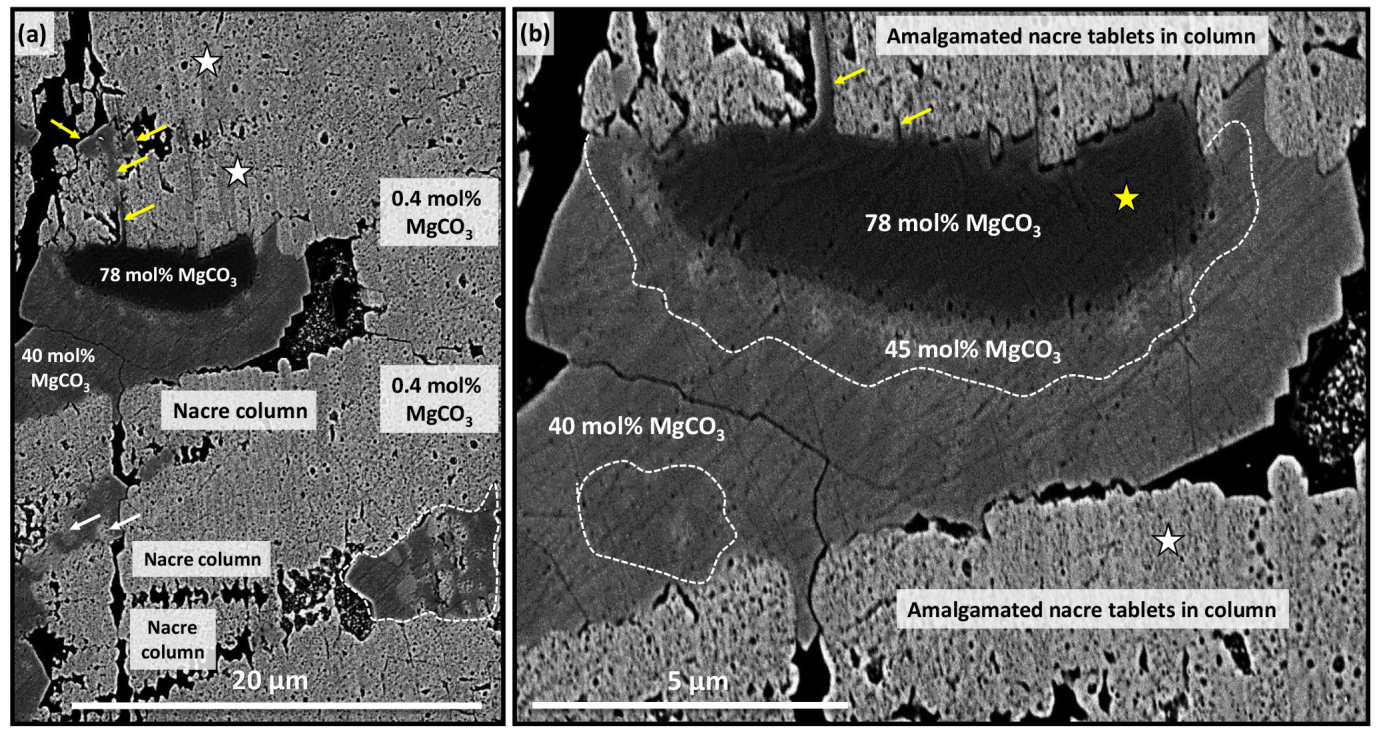

Figure 11. Enlargement of image shown in Fig. $10 \mathrm{~b}$ and d. Mg contents of newly formed metastable Mg-rich carbonates with a calcitetype structure and compositions from dolomitic to about 80 mole $\%$ magnesite. The columnar assembly of tablets around the calcite is still perceivable (white stars in $\mathbf{a}, \mathbf{b})$. Yellow arrows in (a, b) point to the deposition of high-Mg calcite which fills voids and cavities between former nacreous tablets.

teration in a non-stoichiometric solution, the amount of calcite overgrowth was still small; however, a high degree of replacement was achieved. This effect was increased even more by the absence of calcium in the solution. 
The experiments of Perdikouri et al. (2011) demonstrate the importance of porosity and porosity generation for the progress of dissolution-reprecipitation reactions and allude to at least one fundamental difference between biologic and inorganic carbonate hard materials. The absence of primary porosity in inorganic carbonates as well as the (almost complete) drop out of secondary porosity formation. The latter should have been generated at early stages of alteration due to the positive molar volume change that is involved in the aragonite by calcite replacement. However, the only porosity that might have been generated in inorganic carbonate systems arises from the minor difference in solubility between aragonite and calcite. As the solubility products of the two main carbonate phases are similar, very little porosity formation can take place, and consequently, (i) the replacement of inorganic aragonite by inorganic calcite occurs at a very slow rate and (ii) is significantly less pervasive as it is the case when biogenic aragonite is altered into inorganic calcite.

Biological hard tissues are hierarchically organized composite materials where at all scale levels we find an interlinkage of biopolymers with minerals (Levi-Kalismann et al., 2001; Marin and Luquet, 2004; Mayer, 2005; Li et al., 2006; Metzler et al., 2007; Checa et al., 2009). The degradation of biopolymers, being occluded within and between the mineral units of the hard tissue, provides the necessary network of interconnected porosity (Figs. 6, 7, 8, A9, A10, A17). The porosity network not only facilitates alteration, it drives and accelerates it. Our results show that, for biological carbonate tissues, the presence of primary (inherent) and secondary (induced) porosity, together with the characteristics of the porosity network, determines the kinetics and extent of the alteration. Furthermore, the transient character of porosity additionally influences mineral replacement reactions: apart from porosity generation, porosity coarsening and porosity closure are widespread phenomena. These modify the geometry of the porosity network, increase its tortuosity, and reduce its permeability, thereby affecting mass transfer at the interface between the bulk solution and the original mineral phase and hinder physicochemical re-equilibration.

Porosity characteristics are different for the different microstructures investigated in this study (Fig. 1). Primary porosities are present in the shell of A. islandica and in the prismatic shell layer of $H$. ovina. Although the skeleton of the coral Porites sp. is compact, the coral skeleton has a particularly high surface area, as the skeleton consists of various combinations of vertical and transverse elements, with most of these being developed as thin lamellae. Mineral units which comprise these skeletal elements consist of irregularly organized clusters of closely packed aragonitic needles. The centres of calcification are the primary pores in the skeleton of Porites sp. However, these are in general not interconnected, and thus, do not facilitate transfer of solutes towards and away from the reaction front to a large extent. Stacks of calcite fibres in $M$. edulis and the nacreous tablet arrangements in M. edulis and H. ovina are the most compact mi- crostructures investigated in this study. These materials lack primary porosities. Nonetheless, when the shells are altered, the extent of alteration-induced secondary porosity is high in nacreous shell portions, as the occluded intra-tablet membranes and inter-tablet fibrils decompose and leave space behind for extensive fluid circulation.

\subsection{The effect of microstructure - intermediate stages}

A still unsolved problem in palaeoenvironmental reconstruction is the assessment of the extent of diagenetic overprint that compromises the fidelity of geochemical proxies. One strategy is to use numerical approaches for the quantification of the extent of diagenetic alteration. These are based either (i) on the comparison of element to Ca ratios and associated partition coefficients or (ii) the comparison between isotope compositions of the pore fluid and that of the precipitate (Regenberg et al., 2007, and references therein). In a previous study (Casella et al., 2017), we reported experimental data for A. islandica shell material for the replacement reaction of biogenic aragonite by inorganic calcite. In the present study, we extend our previous work with the investigation of additional carbonate skeletons, and thus, other mineral fabrics. One of the major goals of this study is the reliable identification of the first stages of alteration and the attempt to qualitatively assess diagenetic alteration based on microstructural reorganization.

For these targets, we apply statistical grain-area evaluation and develop this approach as a qualitative tool for the detection of incipient to moderate diagenetic overprint. Figures 12 and A16 show relative frequency to grain-area (area of mineral units in the case of biological hard tissues) diagrams for the pristine and the most altered (alteration for 35 days, at $175^{\circ} \mathrm{C}$, in $\mathrm{Mg}$-rich fluid) skeleton equivalents. Grain-area data are obtained from EBSD measurements. A grain is defined as a region that is completely bounded by boundaries that have a misorientation angle larger than a critical value, the critical misorientation value. Griesshaber et al. (2013) empirically determined that a critical misorientation value of $2^{\circ}$ suits best the microstructure of modern carbonate biological hard tissues. By using this value we differentiate between individual mineral units (e.g. fibres, tablets, prisms, columns).

The compilation in Fig. 12 clearly demonstrates the influence of the biogenic microstructure on the ability to withstand or to yield to alteration. The relation of $\log$ (frequency) vs. $\log$ (grain area) is linear for A. islandica, M. edulis calcite and Porites sp. aragonite, and is a clear indication of the fractal distribution in the microstructures of these skeletons.

The least difference in grain areas between pristine and most altered states was observed for A. islandica aragonite (Fig. 12a), while the most significant difference we found for M. edulis fibrous calcite (Fig. 12e). For Porites sp. acicular aragonite and $H$. ovina prismatic and nacreous aragonite we find a perceivable, but small difference in grain area between 

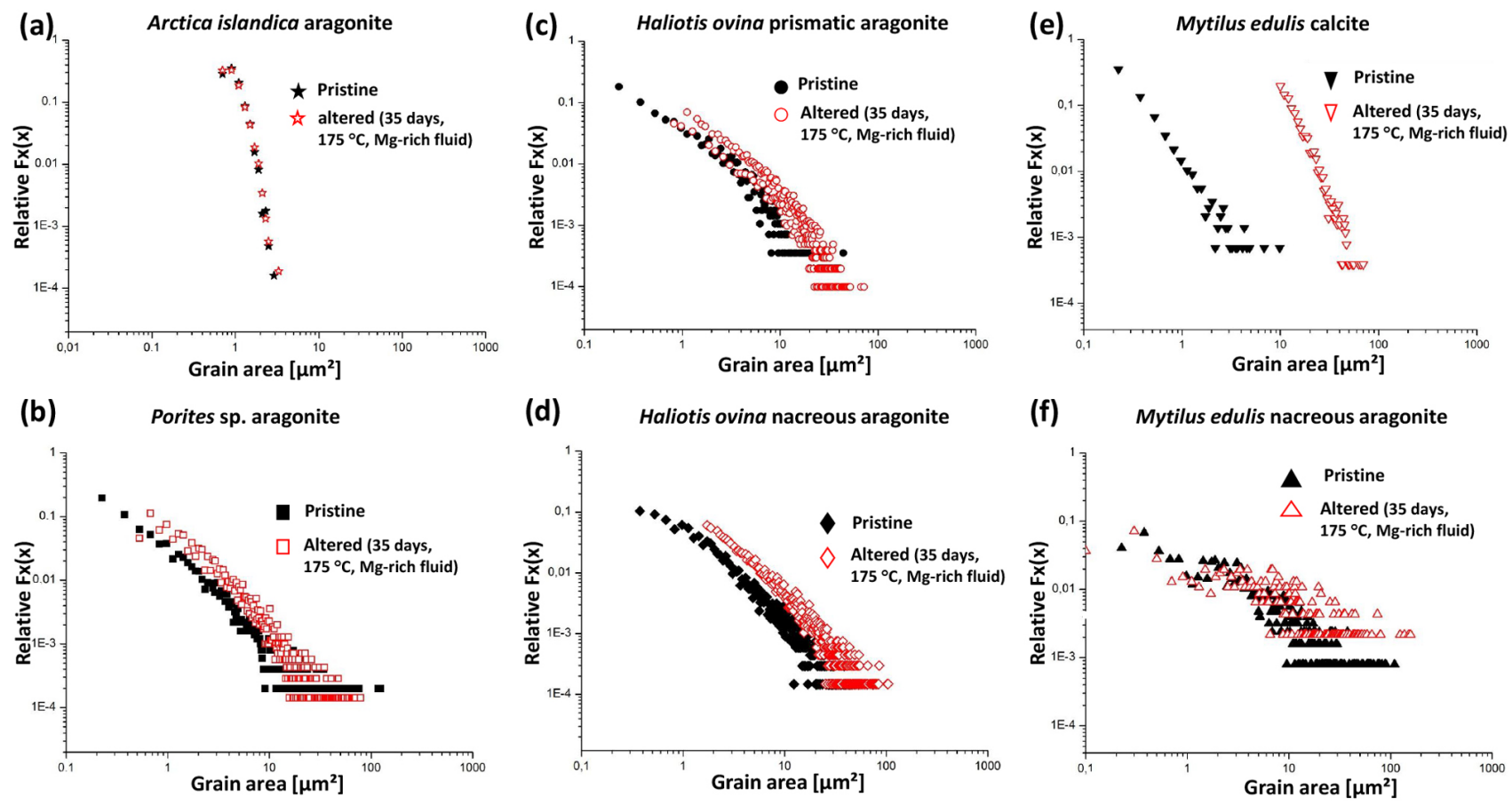

Figure 12. Relative frequency vs. grain-area diagrams for pristine (black) and most altered (red: 35 days, $175^{\circ} \mathrm{C}$, Mg-rich fluid) stages: (a) Arctica islandica, (b) Porites sp., (c, d) Haliotis ovina, and (e, f) Mytilus edulis. Mineral grain area increases with progressive hydrothermal alteration. The least difference in mineral grain area between pristine and most altered stages is present for the microstructure which forms the shell of A. islandica (a), while the most significant difference was observed for M. edulis (e) calcite. For all other investigated microstructures $(\mathbf{b}, \mathbf{c}, \mathbf{d}, \mathbf{f})$ mineral grain area increases with alteration, prior to inorganic calcite formation.

the pristine and the most altered states. For M. edulis nacre the majority of grain-area data overlap. Even though, for this type of microstructure as well some large grains also formed in the altered shell (Fig. A16).

As described previously, subsequent to the destruction of organic sheaths, membranes, and fibrils, the amalgamation of mineral units is the next and a highly drastic step in the overprint process. Inorganic mineral precipitation starts in cavities between the mineral units and in voids within them (e.g. Figs. 7, A17; Casella et al., 2018a, b). It is important to note that this void filling occurs prior to carbonate phase replacement, and thus, prior to inorganic calcite formation. With EBSD we not only measure patterns of crystal orientation but determine the mineralogical phase of the hard tissue as well. At this early stage of alteration the newly formed crystallites that are deposited between the mineral units retain the phase of the host crystal and often even the crystallographic information of the mineral in the pristine skeleton. Thus, in aragonitic biogenic microstructures, inorganic aragonite will precipitate, while in calcitic biogenic microstructures inorganic calcite will form. Syntactic nucleation of a secondary phase that has the same mineralogical nature as the primary phase is prompted by the reduction of the energy barrier associated with heterogeneous nucleation in contrast to homogenous nucleation from a bulk aqueous solution. This barrier is reduced even further as a result of a perfect match between the crystal lattice of the original and the secondary phase. The reduction in the energy barrier explains the preference of inorganic aragonite formation on biogenic aragonite at the first stages of the alteration process, rather than the crystallization of the more stable inorganic calcite.

However, due to its composite nature, biogenic aragonite is more soluble than inorganic aragonite and even more soluble than inorganic calcite. Thus, an aqueous solution in equilibrium with biogenic aragonite is supersaturated with respect to both: inorganic aragonite and inorganic calcite. As aragonite nucleation on existing biological aragonite can be epitactic, the much better match across the interface makes it more likely that inorganic aragonite is formed on the preexisting biogenic aragonite, even though calcite is the more stable phase at Earth's surface pressure and temperature conditions. Free energies and solubilities of the two carbonate phases are close enough that the lower energy barrier associated with epitactic nucleation kinetically favours the formation of new aragonite on the surface of the pre-existing aragonite (Fernández-Díaz et al., 2009; Roncal-Herrero et al., 2017; Cuesta Mayorga et al., 2018). This feature also has been observed in nature. Hover et al. (2001) report early diagenetic overprint of foraminifera and green algae skeletal hard tissues and demonstrate that the overprint mecha- 
nism is the coupled process of dissolution and reprecipitation. The authors find thin overgrowths on the mineral units of the original hard tissues and show that the precipitated material is largely similar in composition and structure to that of the host crystallites. Accordingly, aspect ratios of the mineral units change as their original morphologies become distorted (Figs. 7, A8, A17), and compaction of the hard tissue is the result (e.g. nacre tablets). Hence, even though already altered, the gross microstructure of the shell or skeleton is, at this early stage of alteration, not modified to a large degree. We observe that alteration occurs in two stages: (1) related to the original carbonate phase of the hard tissue, overgrowth of inorganic aragonite or inorganic calcite in voids and pores without major destruction of the original microstructure, and (2) phase replacement, with new phase formation and distortion of the original microstructure, up to its complete destruction. These processes involve the constant rearrangement of pores, which in this case is driven by the free energy reduction associated with the increase in the volume to surface ratio of the mineral units.

We observed the above described features for all investigated microstructures (Fig. 12b to f) except for the aragonitic microstructure of the shell of the bivalve A. islandica (Fig. 12a). Aragonitic grains in A. islandica shell are small and are embedded in a network of biopolymer fibrils (Casella et al., 2017). The thin fibrils are easily destroyed when altered and leave behind a network of voids and cavities, which facilitate fluid infiltration and permeation through the shell. In addition, the large number of small mineral units gives rise to exceedingly large surface areas where the fluid can get into contact with the mineral. Carbonate phase alteration kinetics in A. islandica shell is sluggish at first. However, once the nucleation barrier is overcome and the alteration process is started, it proceeds instantly (Figs. 2a, A4a; Casella et al., 2017). Thus, overgrowth of inorganic aragonite in voids and mineral unit amalgamation are masked by the rapid replacement of biogenic aragonite by inorganic calcite. The high volume of interconnected porosity and the presence of the thermodynamically less stable biogenic aragonite explain why alteration in A. islandica becomes active after such a short time when being in contact with the diagenetic fluids. The topological characteristics of porosity facilitates the coupling between the rate of aragonite dissolution and the rate of calcite reprecipitation. This, in turn, explains the minor difference in mineral unit and grain area found in the hard tissue of $A$. islandica between the pristine and the most altered states (Fig. 12a).

In contrast, $M$. edulis calcite shows the most significant difference in grain area between the pristine and the most overprinted states (Fig. 12e). When altered, the morphology of calcite fibres becomes distorted (Fig. A8a) and fibre amalgamation is substantial leading to the formation of large and highly irregularly shaped mineral units (Fig. A8b). In the pristine state, calcite co-orientation strength is high in M. edulis, we find a single-crystal-like distribution of $c^{*}$ and $a^{*}$ axes (Figs. 6 and 7 in Schmahl et al., 2012). Hence, many neighbouring calcite fibres are highly co-aligned, a circumstance that favours the amalgamation of similarly oriented fibres (Fig. A8b). The nacreous shell layer in M. edulis is little affected by alteration (Figs. 12f, A16a, b), even though nacre tablet amalgamation is readily perceivable. The nacreous shell part grows to a compact entity and becomes sealed and protected against fluid infiltration. This explains the observation of remnants of pieces of nacreous shell surrounded by calcite (Brand, 1994) as well as the prevalence of the nacreous shell part of $M$. edulis relative to calcitic shell pieces in seashore sediments.

Nacre in $H$. ovina behaves slightly differently when hydrothermally altered (Figs. 12d, A16a, c). In H. ovina, nacre tablets are assembled to columns and tablet dimensions are smaller than those present in M. edulis. In both shells, that of $M$. edulis and of H. ovina, nacre tablets are encased by organic sheaths (Addadi et al., 2006; Checa et al., 2006, 2009, 2011; Barthelat and Espinosa, 2007). Compared to M. edulis nacre, nacre in $H$. ovina has a larger organic-mineral interface and mineral surface area per volume fraction of shell. Nacreous tablet amalgamation and compaction occurs in the shell of $H$. ovina as well. In contrast to M. edulis, H. ovina nacre exhibits a distinct increase in grain size in the altered hard tissue. Due to the larger interface and surface area in H. ovina nacre alteration fluids infiltrate the shell more intensely, and dissolution-reprecipitation occurs to a higher extent. Hence, overprint is more significant and becomes more evident. The same argument holds for prismatic aragonite found in H. ovina (Fig. 12c) and acicular aragonite in Porites sp. (Fig. 12b), where, in both examples, prior to replacement of biogenic aragonite by inorganic calcite, mineral units increase in size in the altered skeleton. It is important to note that the mineral unit size increase is accompanied in $\mathrm{H}$. ovina and Porites sp. by partial closure of the porosity, as the newly formed calcite is completely devoid of pores (Figs. 8, $10,11, \mathrm{~A} 5 \mathrm{~b}, \mathrm{~A} 10 \mathrm{~b})$. The partial closure of pores explains the low degrees of replacement that we find in these hard tissues even after long alteration periods (Fig. 2).

Our study clearly shows that, of the investigated aragonitic microstructures, nacre is the most resistant to replacement with calcite, irrespective of the assembly pattern of the tablets to columns or sheets. Porosity closure and mineral unit (nacre tablet) amalgamation at first completely recasts the original microstructure - however, they preserve the original phase (Figs. 9a, A17a, b). Hence, even though nacreous aragonite is still present in the shell as aragonite, it is an overprinted aragonite that holds little of the original microstructural or geochemical signature. With an increasing degree of alteration, the "remoulded" aragonite becomes replaced by inorganic calcite. The outcome of our alteration experiments leads to the conclusion that the microstructural signature is lost first (prior to a complete loss of the original mineralogical phase) while the geochemical information is still retained in the mineral, at least to some degree. When alteration takes 
place in a Mg-rich fluid, metastable high-Mg carbonates are present at the original-material - newly formed product interface, in addition to the "final" inorganic, low-Mg calcite. These high-Mg carbonates have a calcite-type structure and $\mathrm{Mg}$-contents ranging from dolomitic to about $80 \mathrm{~mol} \% \mathrm{mag}$ nesite (Figs. 9a, 11). We clearly see an evolution in fluid composition at the alteration front due to an evolution in cationanion exchange between the alteration fluid, the overprinted original, and the newly formed carbonate products.

\subsection{Implications for preservation in the fossil record}

Several studies have shown that in modern cold and warm water environments aragonite dissolution takes place during burial diagenesis (e.g. Cherns et al., 2008, and references therein). It has been further demonstrated that, in Palaeozoic marine fossil faunae, the taxa with calcitic skeletons prevail. This is an indication of preferential loss of aragonitic shells and skeletons due to dissolution during diagenetic overprint (e.g. Wright et al., 2003; James et al., 2005). In addition to preferential carbonate phase preservation, experimental studies document that the microstructure of the biogenic skeleton influences fossil preservation (e.g. Harper, 1998; Kidwell, 2005), leading to a possibly distorted notion of palaeoecological and evolutionary patterns. Accordingly, laboratorybased hydrothermal alteration experiments accounting for microstructural as well as mineral phase variability offer important insights into the fate of carbonate hard tissues (i) during early dissolution in shallow burial, and (ii) surviving dissolution and preservation in the fossil record.

Do we see resemblances between the microstructural and chemical outcome of our alteration results and microstructural and geochemical features of fossilized hard tissues? It is remarkable that, even though our experiments lasted for only 35 days, were carried out at a single temperature, and were performed in the presence of only one type of alteration fluid, there is much overlap between our experimental products and carbonates which underwent diagenesis. Several decades ago Friedman (1964) and Land (1967) reported on the early diagenesis of skeletal carbonates and carbonate sediments exposed to marine waters. The biological carbonates retained their original mineralogical and textural characteristics. They found that biogenic aragonite was dissolved for the reprecipitation of low-Mg calcite, with high-Mg calcite being an intermediate phase. $\mathrm{Mg}$ was removed from high-Mg calcite to yield low-Mg calcite, and, on a micrometre scale, without any textural change (Friedman, 1964). Land (1967) observed that skeletal aragonite was altered much quicker relative to non-skeletal aragonite grains. Brand (1989) investigated the replacement of biogenic aragonite by calcite in fossil molluscs (Boggy Formation, Oklahoma, USA). Screening of the mineralogy, microstructure, and chemical composition indicated that primary nautiloid aragonite was gradually replaced by diagenetic low-Mg calcite. During the initial stages of alteration, nacreous tablets fused to larger units (Brand,
1989). With further alteration, amalgamated nacreous aragonite was replaced by fine- or coarse-grained, low-Mg calcite. Brand (1989) noted that the composition of the original aragonite determined the elemental and isotopic composition of the calcite in the diagenetically altered shells. Furthermore, the author reported that grain size and surface area play an important role in the process of overprinting. Diagenetically overprinted aragonitic corals were investigated by Sorauf (1980), and Tomiak et al. (2016). The authors observed that during early diagenesis, subsequent to decomposition of organic matrices, aragonitic units formed through fusion of pristine skeletal elements. Pore space became filled prior to burial, with aragonite needles growing syntaxially on existing biogenic aragonite. Subsequent submarine diagenesis led to recrystallization of fibrous aragonite into intermediate, micritic high-Mg calcite. Tomiak et al. (2016) and Regenberg et al. (2007) observed formation of new mineral overgrowth during early diagenesis of coral aragonite and planktonic foraminifera calcite. The latter, at first, retained and corresponded to the carbonate phase of the original pristine skeleton. Wardlaw et al. (1978), Sandberg and Hudson (1983), and Martin et al. (1986) described the influence of skeletal porosity as conduits for alteration fluids during diagenesis. As the replacement of aragonite by calcite is driven by the greater solubility of aragonite relative to that of calcite, during the replacement reaction the diagenetic pore fluid is undersaturated with respect to aragonite, while it is supersaturated with respect to calcite (Maliva et al., 2000). Hendry et al. (1995) proposed, on the basis of differences in degrees of supersaturation, a "two-water diagenetic system" with a slow moving (at the dissolution-reprecipitation front) and a relatively fast moving (bulk pore water) alteration fluid.

In our experiments we detected the following major steps and pathways of alteration: (i) decomposition of biopolymers, (ii) secondary porosity formation on nanometre and micrometre scale levels, (iii) amalgamation of mineral units, (iv) destruction of the original microstructure with subsequent carbonate phase change, and (iv) chemical evolution of the alteration fluid. These stages were also observed in nature. Our experiments, which lasted only for 35 days in comparison to geologic time scales, create the constraint that major and drastic steps of alteration take place at the very initial stages of the overprint process.

Finally, we restate our major question: what determines the preservation potential of a fossil archive? A major factor is the availability of porosity on all scale levels for fluid circulation. This enables a well balanced dissolutionreprecipitation to take place. The result is nucleation and epitactic growth of the original phase in voids and cavities at the sites of degraded biopolymers, leading to amalgamation of mineral units. The final result is the compaction of the entire hard tissue and protection from disintegration. 


\section{Conclusions}

For an evaluation of the resistance of biogenic carbonate for withstanding diagenetic alteration, and an assessment of the ability of the biocarbonate microstructure to become preserved in the fossil record, we investigated the behaviour of six biogenic carbonate hard tissues during experimental hydrothermal alteration. Our main conclusions are as follows:

1. Alteration of biogenic aragonite into inorganic calcite starts along pathways where fluids can penetrate the mineralized tissue. It is fastest in hard tissues which contain primary porosity and are composed of irregularly shaped mineral units embedded in a network of biopolymer fibrils. The latter are easily destroyed providing secondary porosity, and together with the primary pores, ample space is provided for extensive fluid infiltration into, and percolation through, the hard tissue. Moreover, porosity is created at the transition front. This mode of overprint is observed for the prismatic aragonite shell layer of the gastropod Haliotis ovina and for the shell of the bivalve Arctica islandica. Overprinting of these hard tissues is fast and is completed with the formation of irregularly shaped and randomly oriented calcite crystals.

2. The slowest alteration kinetics can be observed when biogenic nacreous aragonite is replaced by inorganic calcite, irrespective of the mode of assembly of the nacre tablets. Alteration proceeds through at least four intermediate stages: (a) decomposition of biopolymers and formation of secondary porosity; (b) lateral and longitudinal amalgamation of nacre tablets; (c) formation of a compact zone of amalgamated aragonite crystals at the alteration front, where the original nacreous microstructure is destroyed but the original mineralogical phase is kept; and (d) complete replacement of the original microstructure and the mineralogical phase by the newly formed mineral product: inorganic calcite. This mode of overprint is observed in the nacreous shell portions of Haliotis ovina and Mytilus edulis.

3. The acicular microstructure of the stony coral Porites sp. is highly resistant to alteration. When altered, aragonite needles amalgamate and form a cemented compact unit; however, they retain at first some morphological aspects of the original hard tissue. Replacement of biogenic aragonite by inorganic calcite starts in Porites sp. at centres of calcification within the coral skeleton, and proceeds from the latter into the hard tissue.

4. For all investigated aragonitic hard tissues we first observe the destruction of the microstructure and subsequently the replacement of the original aragonitic phase by newly formed calcite.
5. Alteration in the Mg-bearing fluid results in the development of a seam of high-Mg calcite between the altered, reworked aragonite and the newly formed calcite. Metastable Mg-rich calcite phases form with $\mathrm{Mg}$ contents that vary between dolomitic to about 80 mole \% magnesite. This high-Mg calcite seam migrates with the alteration and phase transformation front.

6. Differences in grain-area statistics in EBSD maps of pristine and altered skeletal equivalents demonstrates an increase in grain size of the originally biogenic carbonate phase within the altered hard tissues relative to that found in the pristine skeleton. Even though at early stages of alteration the original phase is retained, overprinting has already started with amalgamation of neighbouring crystals and formation of overgrowths. This is most pronounced in the calcitic shell layer of Mytilus edulis and is least observable for the grains which constitute the shell of Arctica islandica.

7. Due to formation of overgrowths, preservation of the original phase is not a reliable indicator for original elemental and isotope signals.

Data availability. This paper is mainly based on EBSD data sets which contain over 500000 single measurement points each. The data sets are extremely large in data volume and cannot be stored in volume-limited databases; thus our data are unsuitable for a public access. In addition, EBSD data-specific and chargeable software is necessary for data evaluation. 


\section{Appendix A}
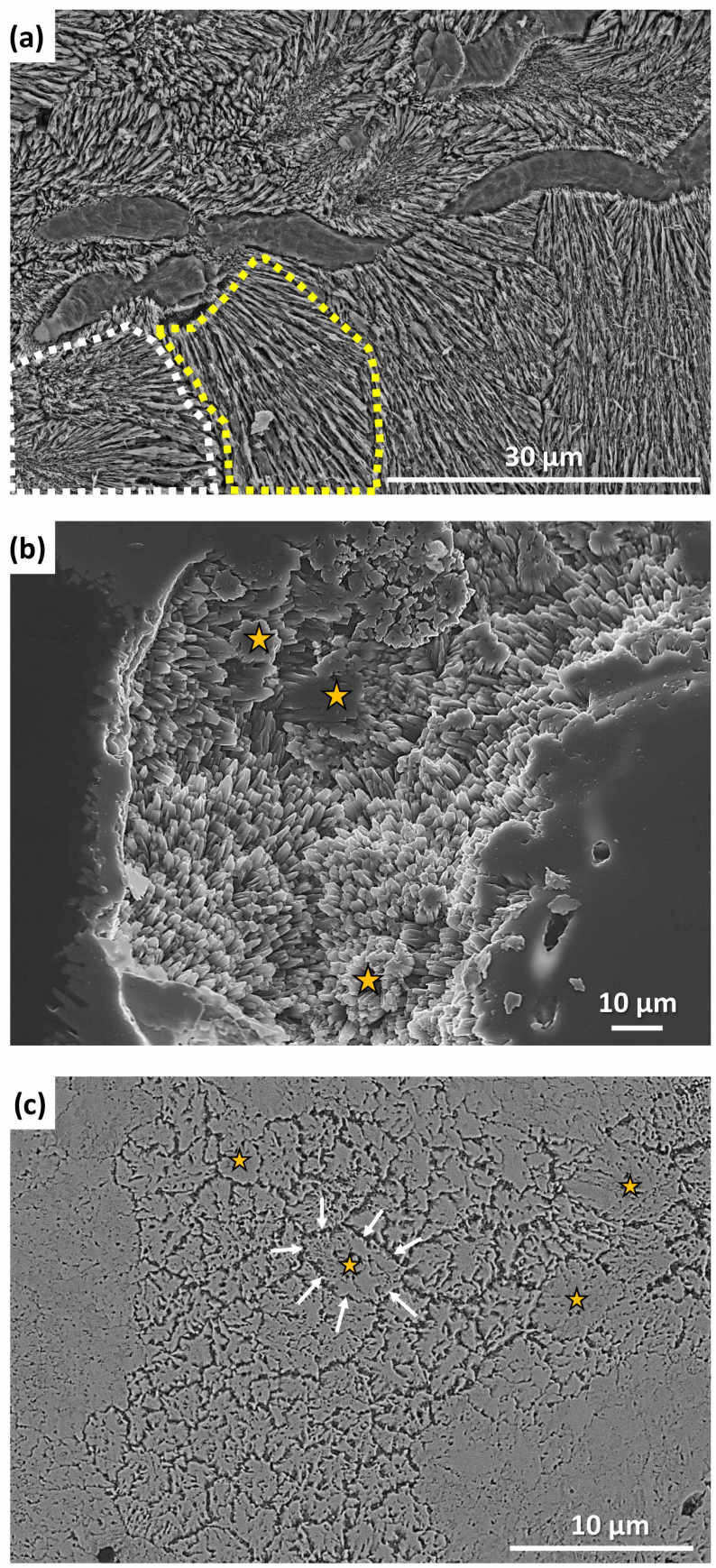

Figure A1. SEM micrographs showing the acicular microstructure of the modern scleractinian coral Porites sp. (a), differently sized and oriented spherulites constitute the skeleton of Porites sp. When fractured in 2-D, differently oriented individual mineral units consisting of diverging aragonite needles emerge (encircled with white and yellow dashed lines in a). (b) Fracture surface image with top view onto bundles of aragonite needles. When needles show some co-alignment, subunits with a closer packing of aragonite needles develop (yellow stars in b). On flat, 2-D surfaces (c) these co-aligned needles form irregularly shaped units with roundish morphology (yellow stars in c) that are separated from each other by a multitude of cavities (e.g. white arrows in c). 

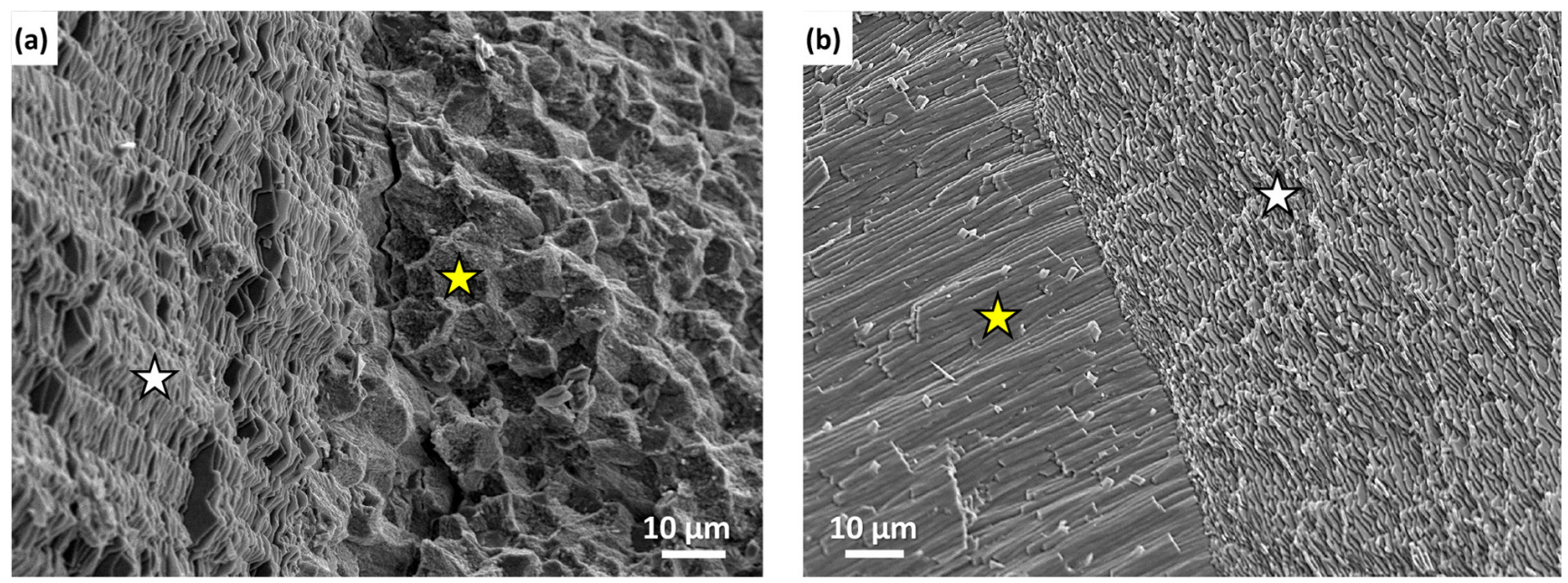

Figure A2. SEM micrographs of fracture surfaces showing the microstructures of modern shells of (a) gastropod Haliotis ovina, and (b) bivalve Mytilus edulis. White stars in (a) and (b) indicate the columnar and brick-and-mortar nacre in H. ovina and M. edulis, respectively, whereas yellow stars in (a) and (b) point to aragonitic prisms in H. ovina and calcite fibres in M. edulis, respectively.

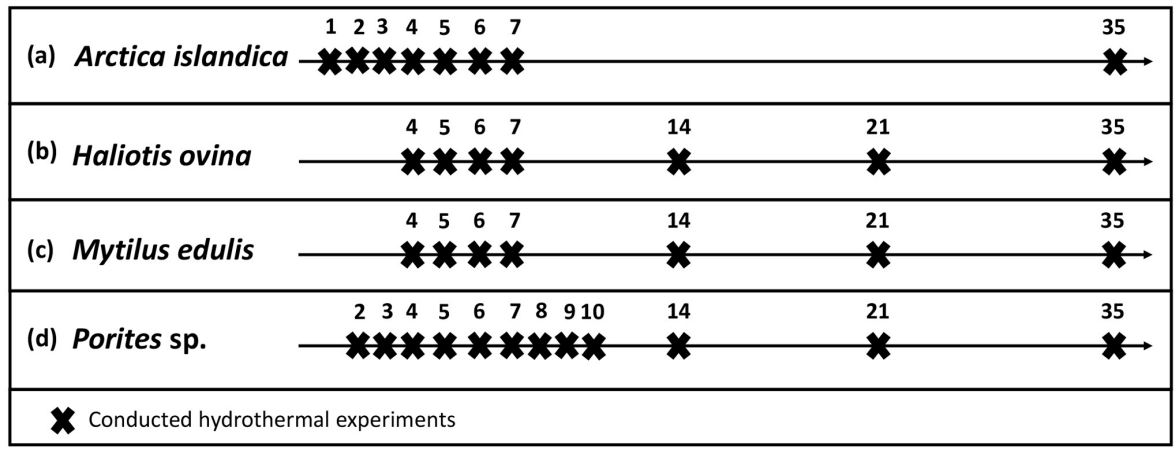

Figure A3. Schematic time line illustrating hydrothermal alteration times. (a) Arctica islandica, (b) Haliotis ovina, (c) Mytilus edulis, and (d) Porites sp. Alteration time varied between 1 and 35 days. 

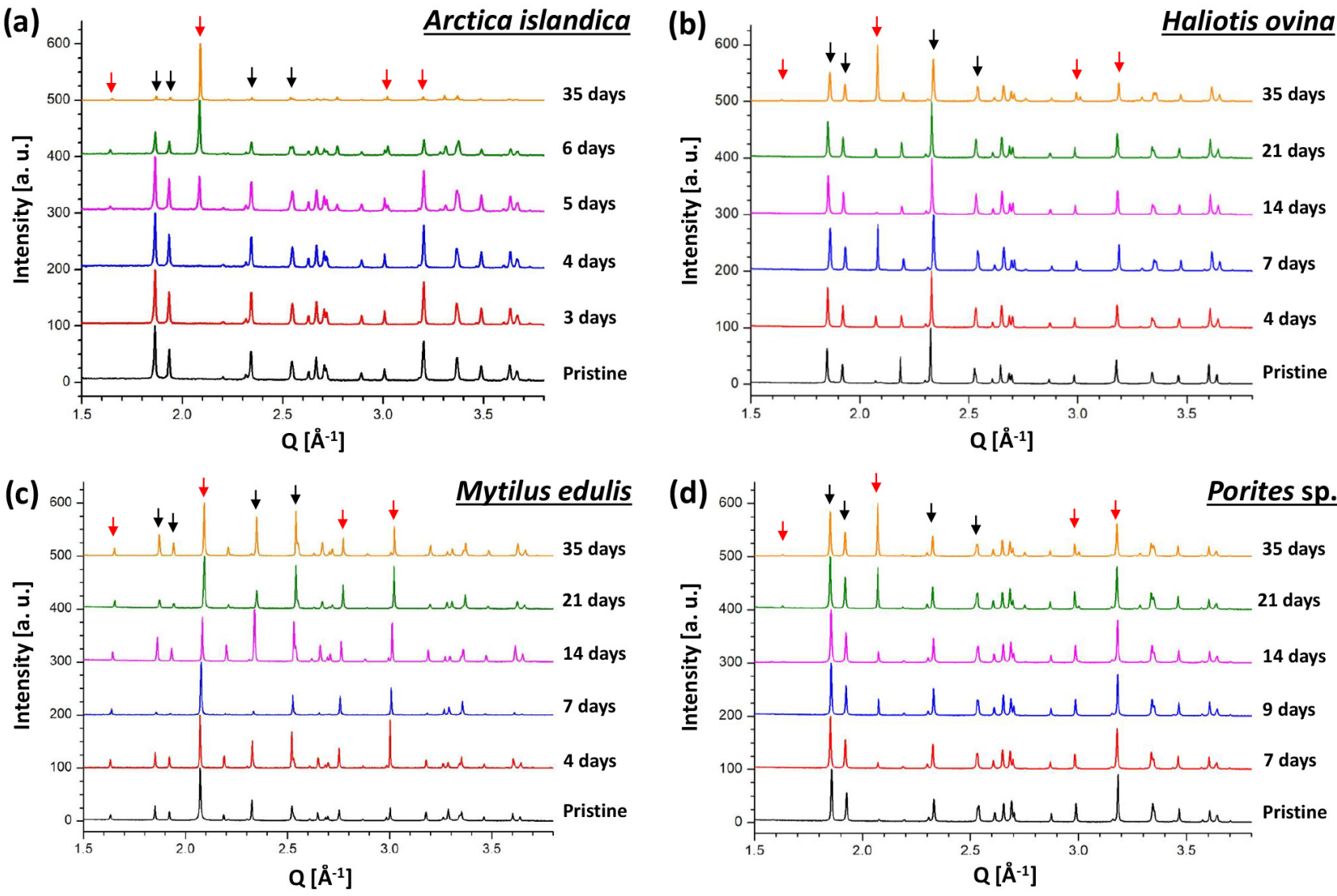

Figure A4. Selected X-ray diffractograms for pristine and hydrothermally altered (a) Arctica islandica, (b) Haliotis ovina, (c) Mytilus edulis, and (d) Porites sp. specimens (red arrows: calcite, black arrows: aragonite). Alteration was performed at $175^{\circ} \mathrm{C}$ in a $\mathrm{Mg}$-rich fluid simulating burial alteration $\left(100 \mathrm{mM} \mathrm{NaCl}+10 \mathrm{mMMgCl}_{2}\right.$ aqueous solution) and was carried out in a time range between 1 and 35 days. 

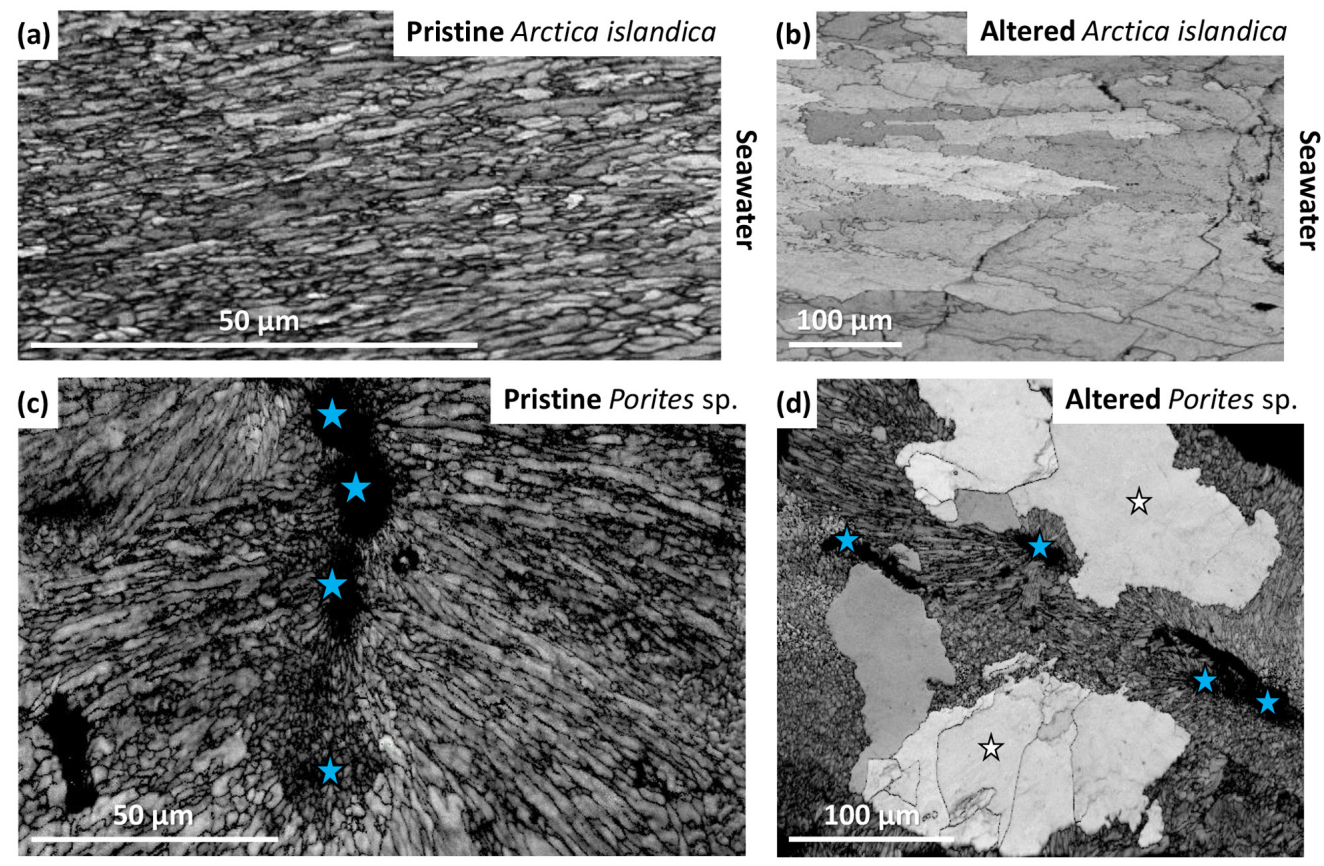

Figure A5. EBSD band contrast measurements illustrating the difference in microstructure between the pristine and the most altered (a, b) Arctica islandica shells, and (b, c) Porites sp. skeletons. Hydrothermal alteration lasted for 35 days and was carried out at $175^{\circ} \mathrm{C}$ in a fluid simulating burial diagenesis ( $100 \mathrm{mM} \mathrm{NaCl}+10 \mathrm{mM} \mathrm{MgCl}_{2}$ aqueous solution). (a) The microstructure of the inner shell layer of pristine A. islandica consists of small round to elongated aragonitic mineral units. (b) Hydrothermal alteration for 35 days induces the replacement of biogenic aragonite by inorganic calcite comprising large calcite crystals. (c) Aragonite needles growing outward from centres of calcification (blue stars in c) are distinctive features of the microstructure of pristine Porites sp. skeletons. When altered for 35 days, large calcite crystals (white stars in d) develop and grow outward from the centres of calcification (blue stars in d). Even after 35 days of alteration, relicts of the original biogenic, acicular coral microstructure are still present and surround the newly formed calcite (d). 


\section{Haliotis ovina}
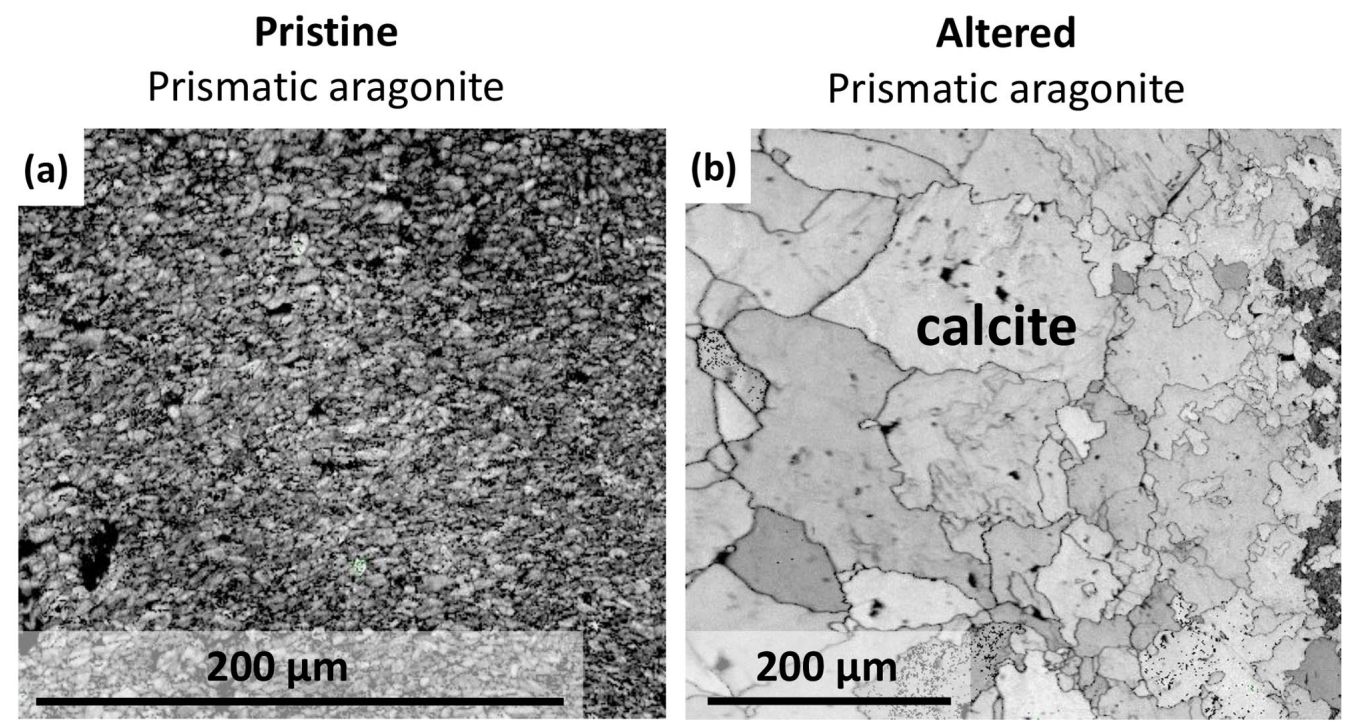

Pristine

Nacreous aragonite
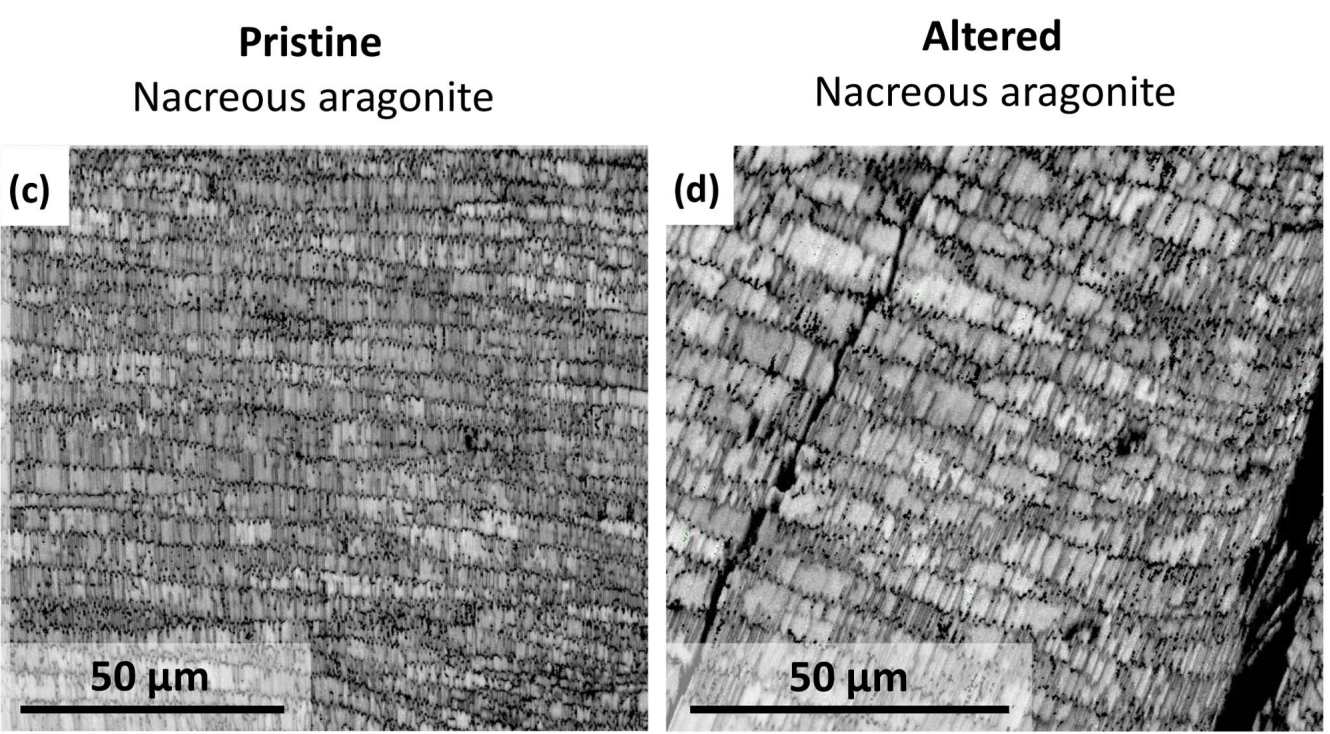

Figure A6. EBSD band contrast measurements illustrating the difference in microstructure between pristine and hydrothermally altered shells of the gastropod Haliotis ovina. Alteration occurred at $175^{\circ} \mathrm{C}$ in $\mathrm{Mg}$-rich fluid $\left(100 \mathrm{mM} \mathrm{NaCl}+10 \mathrm{mMMgCl}_{2}\right.$ aqueous solution) and lasted for 35 days. (a) Prismatic aragonite comprising the pristine outer shell layer. (b) After 35 days of alteration, calcite crystals, which increase in size towards the centre of the hydrothermally altered shell, form. (c) Columnar nacre in the pristine shell, and (d) in the hydrothermally altered specimen. Nacre is highly persistent through the alteration conditions applied in our experiments. The original microstructural features are well retained, even after 35 days of alteration. 

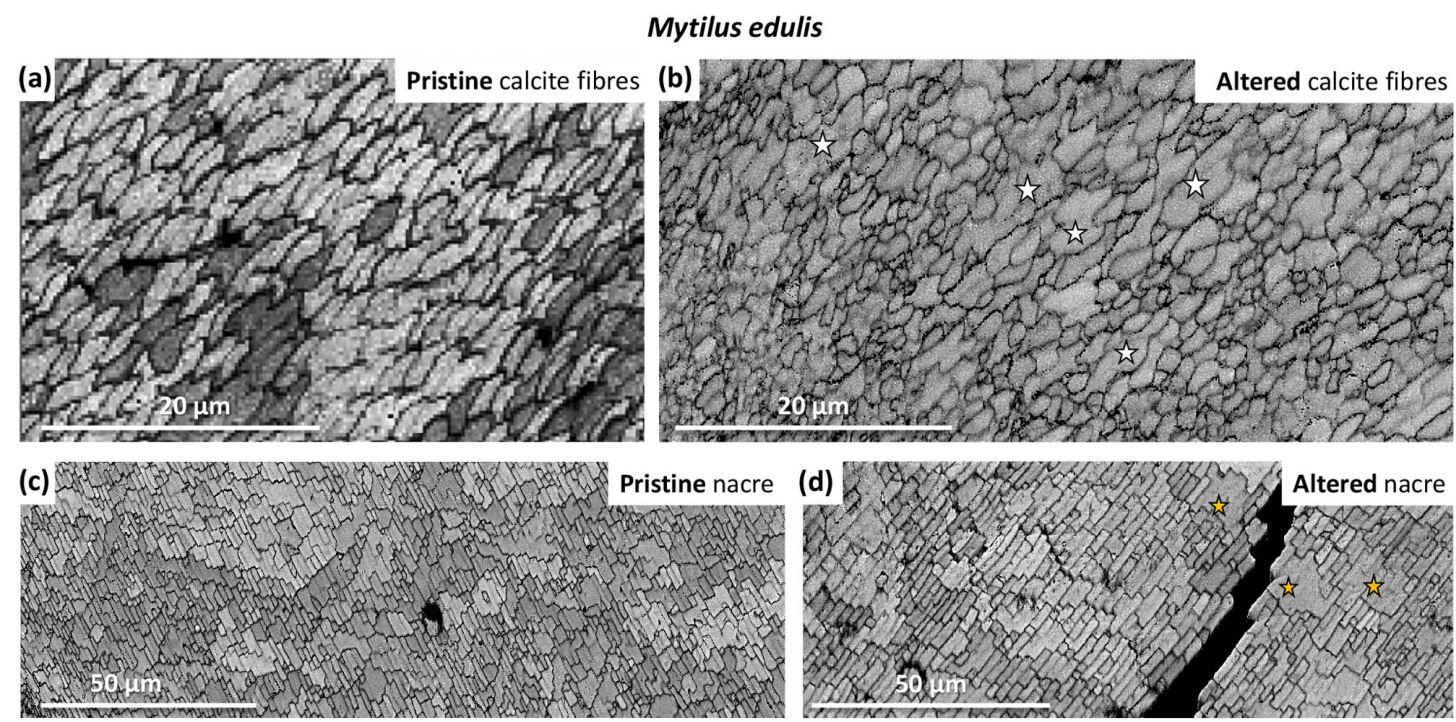

Figure A7. EBSD band contrast measurements illustrating the microstructures in pristine and hydrothermally altered Mytilus edulis shell. Alteration lasted for 35 days at $175^{\circ} \mathrm{C}$ and was carried out in a fluid simulating burial diagenesis $(100 \mathrm{mM} \mathrm{NaCl}+10 \mathrm{mMMgCl} 2$ aqueous solution). (a, b) Pristine and overprinted calcite fibres. (c, d) Pristine and overprinted nacre tablets. The nacre is assembled in a brick-andmortar arrangement. Even though the nacreous microstructure is very little affected by alteration, some amalgamation of nacre tablets (yellow stars in d) is perceivable in the altered sample. 

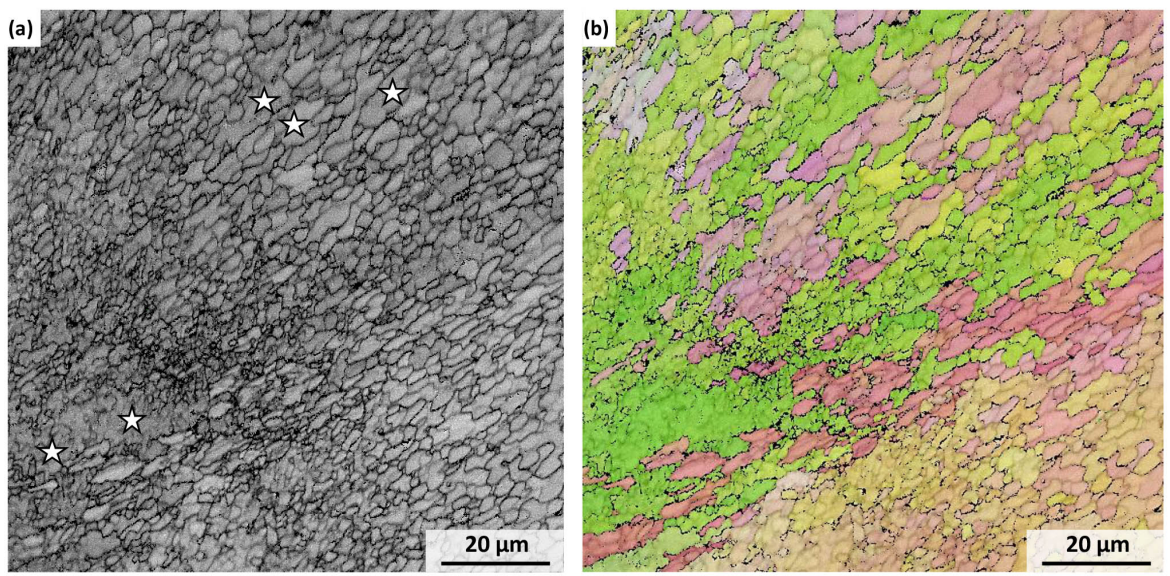

Figure A8. EBSD band contrast (a) and colour-coded orientation maps (b) of hydrothermally altered ( 35 days at $175^{\circ} \mathrm{C}$ in the presence of Mg-rich burial water) Mytilus edulis calcite fibres. Significant distortion of fibre morphology and amalgamation into irregularly shaped and sized units can be observed (white stars in a).
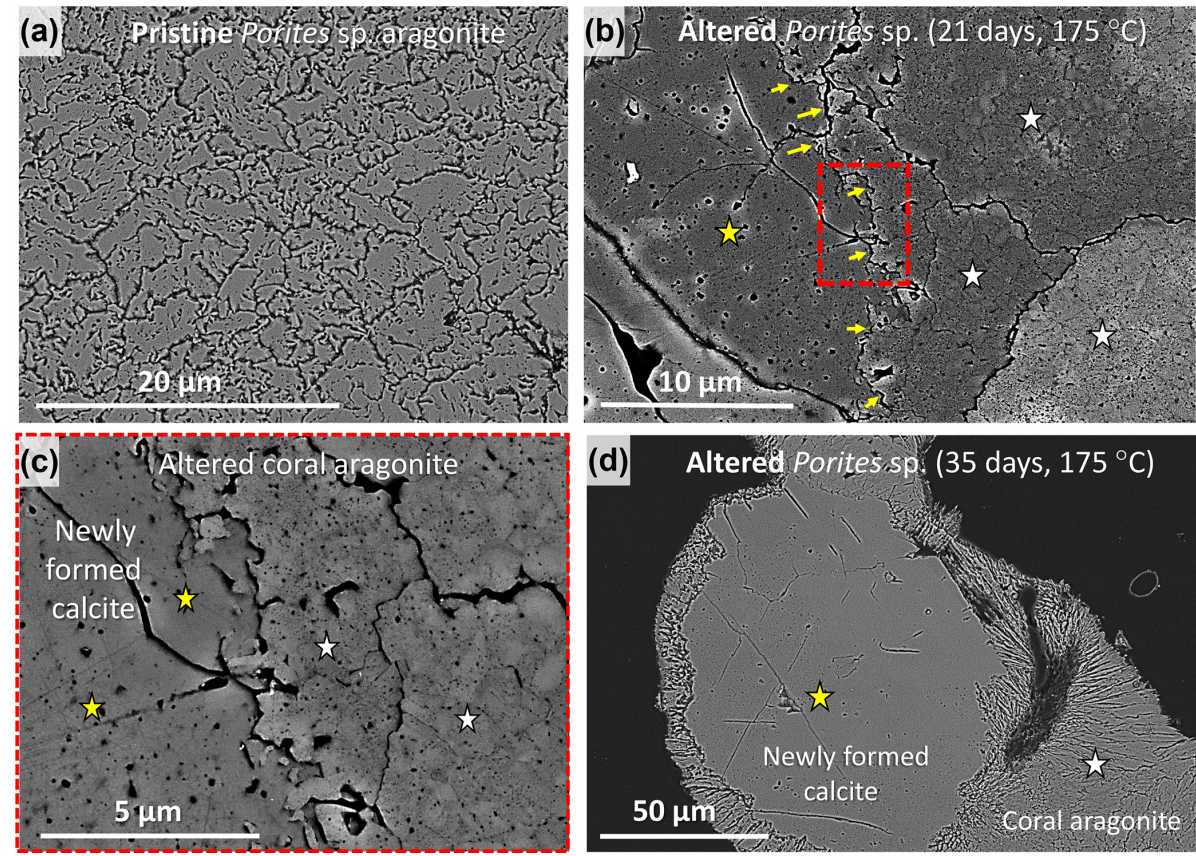

Figure A9. Mineral units in the pristine and altered coral skeleton. (a) SEM image of pristine Porites sp. showing irregularly shaped, roundish aragonite entities separated from each other by cavities. (b, c) SEM images of altered Porites sp.; white stars: altered aragonite; yellow stars: coral aragonite now replaced by calcite. Yellow arrows in (b) point to the aragonite-calcite border. Red dashed rectangle in (b) indicates the skeletal region which is shown with a zoom-in in $(\mathbf{b}, \mathbf{c})$. Note the amalgamation of mineral units in the overprinted, but still aragonitic skeleton. (d) Porites sp. skeleton altered for 35 days. Large calcite crystal (yellow star in d) extending towards the rim of the skeleton framed by coral aragonite (white star in $\mathbf{d}$ ). 

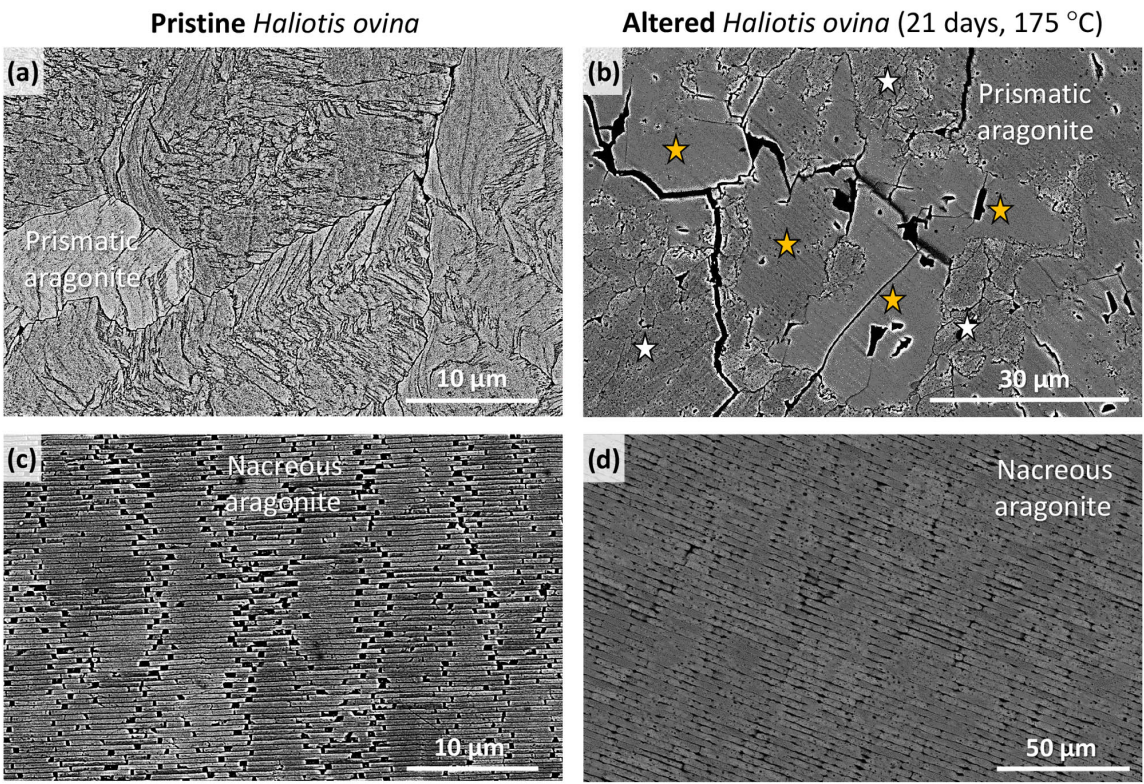

Figure A10. SEM images of pristine and altered Haliotis ovina prismatic $(\mathbf{a}, \mathbf{b})$ and nacreous $(\mathbf{c}, \mathbf{d})$ aragonite. In comparison to the pristine microstructures, amalgamation of mineral units is one of the major characteristics of both microstructures (prismatic and nacreous) in the altered shell. (b) New calcite formation (yellow stars in b) is significant in the prismatic shell layer (white stars in b), while it is absent in the nacreous shell layer (d). Note that the compactness of the nacreous microstructure is due to tablet amalgamation in (d), as seen more clearly in Fig. 4d.
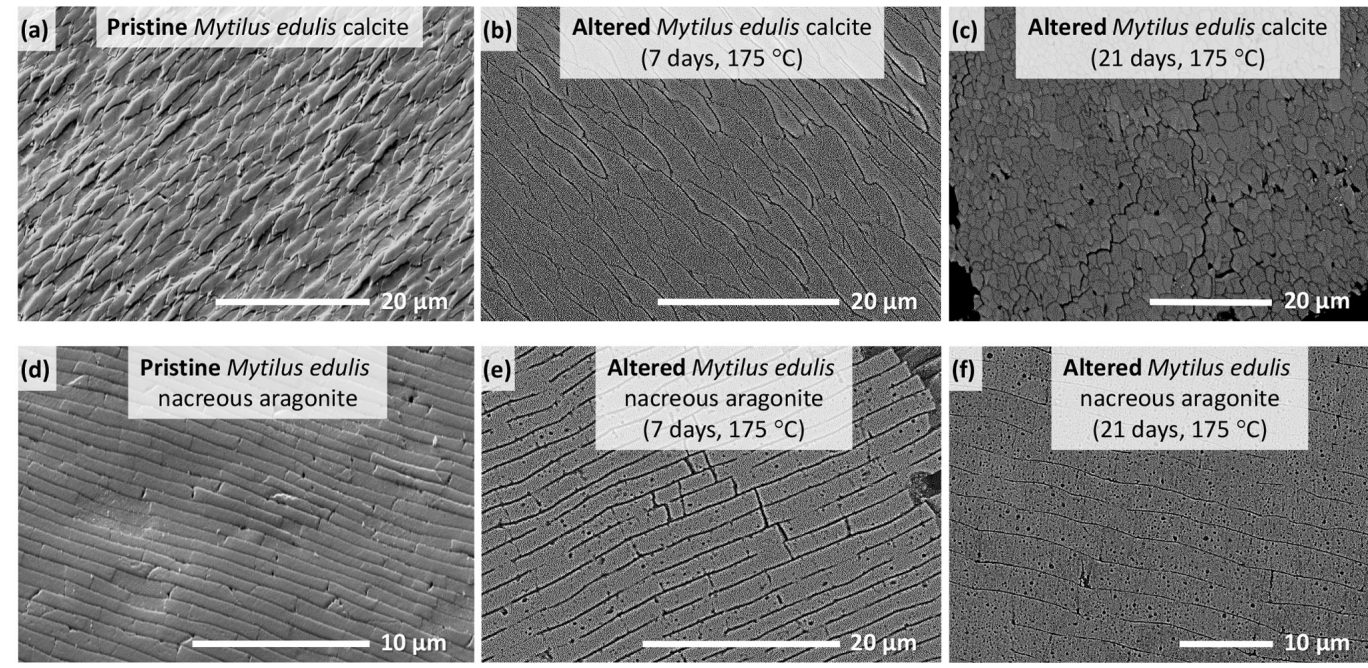

Figure A11. SEM images depicting microstructural characteristics of pristine and altered Mytilus edulis shell calcite and aragonite. (a, d) cross-sections of pristine calcite fibres (A), and nacre tablets (d). (b, c) altered calcite fibres with the clear distortion of fibre morphology (c) after 21 days of alteration. (e, f) Nacre tablets altered for 7 and 21 days. After 7 days of alteration, the development of porosity already is evident within nacre tablets (e). This porosity increases significantly, in addition to fibre amalgamation, with progressive alteration (f). 


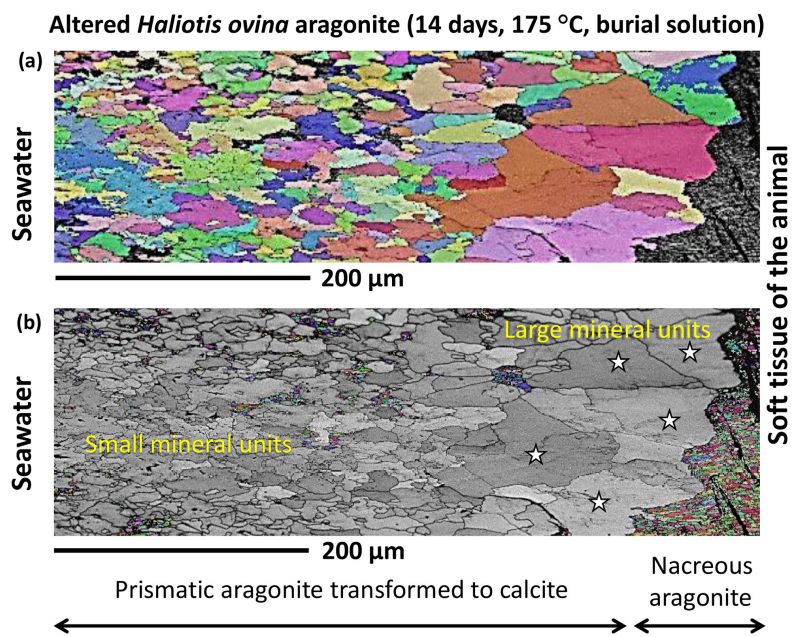

Figure A12. Retention of some characteristic features of the original biogenic microstructure with progressive alteration. In pristine Haliotis ovina there is a gradation in mineral unit size, such that large mineral units are in the central part of the shell next to the nacre (white stars in b). These decrease in size towards the outer rim of the skeleton. (a) EBSD band contrast and colour-coded orientation image showing newly formed calcite in colour and nacreous aragonite in grey. (b) EBSD band contrast and colour-coded orientation image showing newly formed calcite in grey, nacreous and prismatic aragonite in colour.

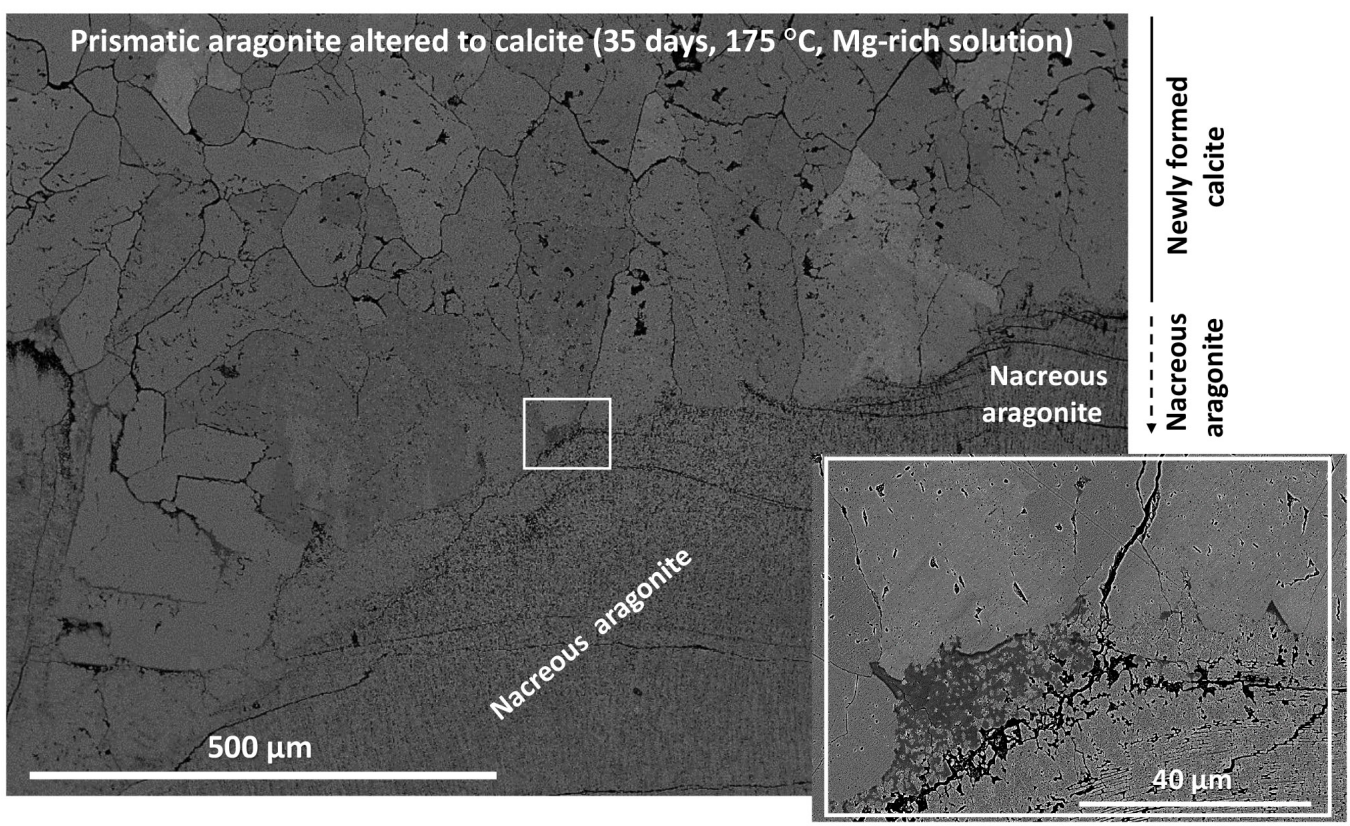

Figure A13. SEM image showing an overall view of a cross-section through the shell of Haliotis ovina which was altered for 35 days at $175^{\circ} \mathrm{C}$ in $\mathrm{Mg}$-rich solution. The white rectangle indicates the shell area where the insert of Figs. 9 and A13 zooms into. 

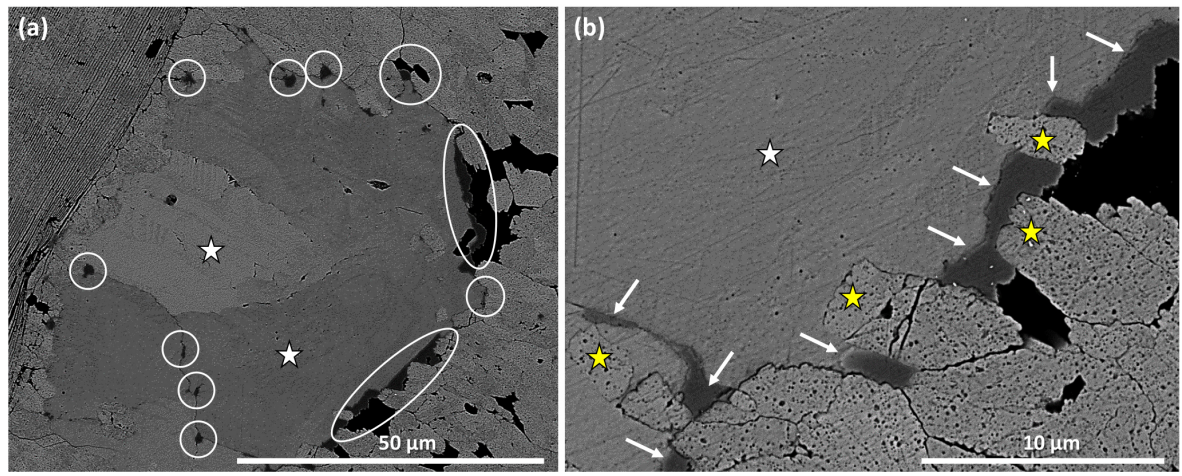

Figure A14. Shell segment of Haliotis ovina altered for 14 days at $175^{\circ} \mathrm{C}$ in the presence of a Mg-rich solution. Large newly formed calcite units grow from prismatic aragonite and are present within the shell next to the nacre (white stars in $\mathbf{a}$ and $\mathbf{b}$ ). These are seamed by patches of a high-Mg carbonate phase (encircled in $\mathbf{a}$, indicated by white arrows in $\mathbf{b}$ ), mainly located between the newly formed calcite and the overprinted prismatic aragonite. The newly formed calcite is framed by altered prismatic argonite, which has not yet been replaced by calcite (yellow stars in b).
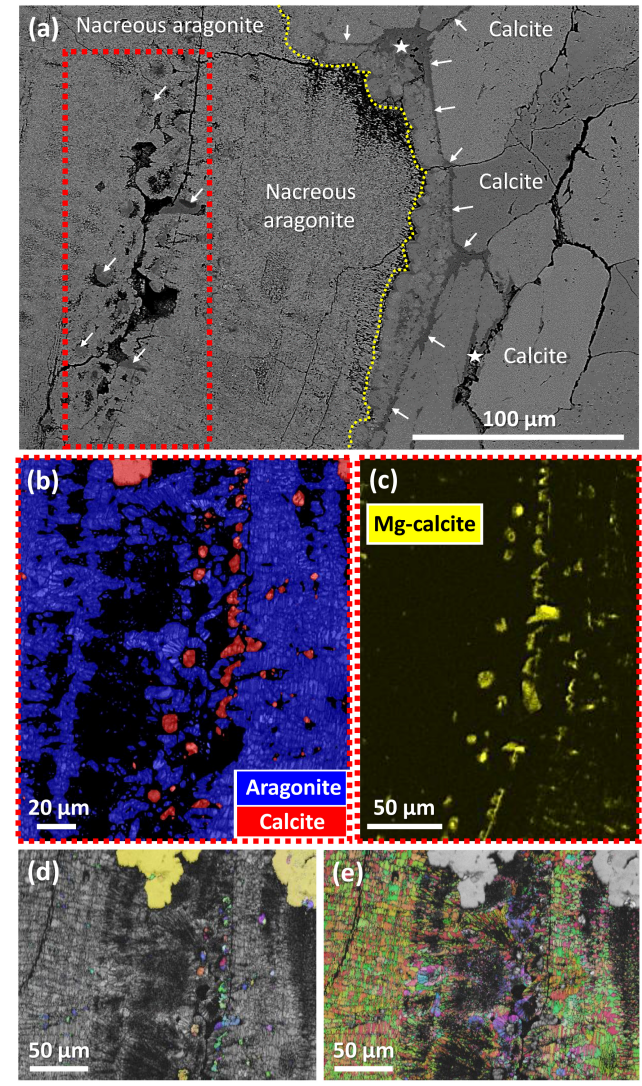

Figure A15. Contact between newly formed calcite and overprinted nacreous aragonite in hydrothermally altered Haliotis ovina. Alteration occurred for 14 days at $175^{\circ} \mathrm{C}$ in the presence of a Mg-rich solution. (a) SEM image showing an overview. Accumulations of high-Mg calcite within calcite can be observed (white stars and white arrows in a) at the alteration front to nacreous aragonite. Red dashed rectangle in (a) indicates the shell areas shown in (b) and (c). (b) Carbonate phase determination derived from EBSD. (c) Distribution pattern of high-Mg calcite determined with EDX. (d, e) EBSD band contrast (greyscale) and orientation maps (in colour). (d) Band contrast map giving an overview in grey of the aragonitic microstructure which is overlain in colour by the distribution pattern of calcite. (e) Aragonite distribution and mode of orientation in colour overlain by the distribution of calcite in grey. 


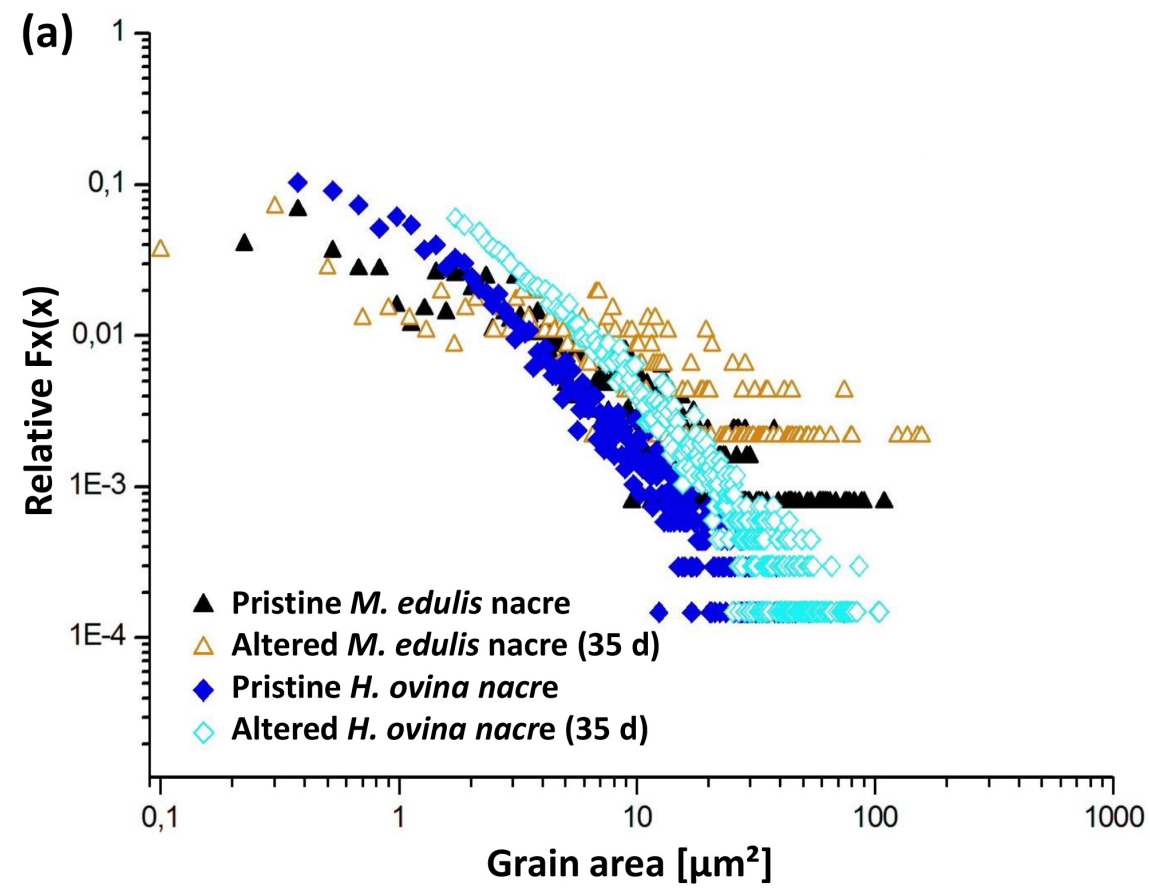

(b)

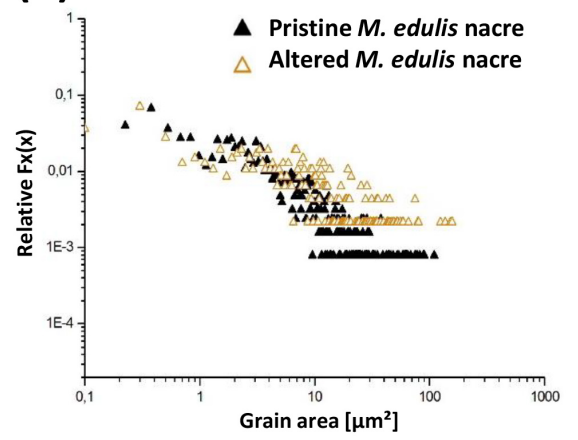

(c)

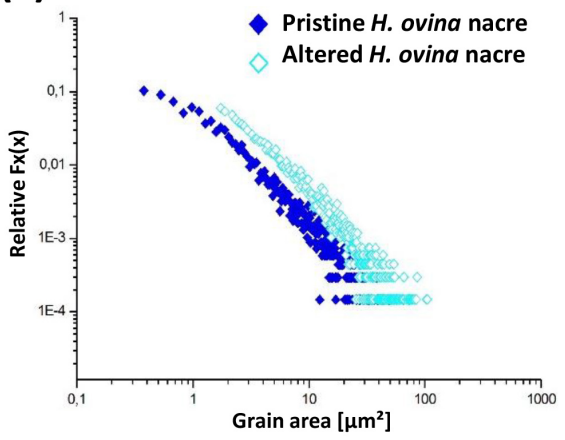

Figure A16. Relative frequency vs. mineral grain-area diagrams for pristine and most altered Mytilus edulis, and Haliotis ovina nacreous aragonite, respectively $(\mathbf{a}, \mathbf{b}, \mathbf{c})$. For both nacreous structures mineral unit growth (tablet amalgamation) can be observed after alteration. This feature is most pronounced for tablet dimensions and mode of assembly in Haliotis ovina nacre. Alteration occurred for 35 days in the presence of Mg-enriched fluid at $175^{\circ} \mathrm{C}$. 

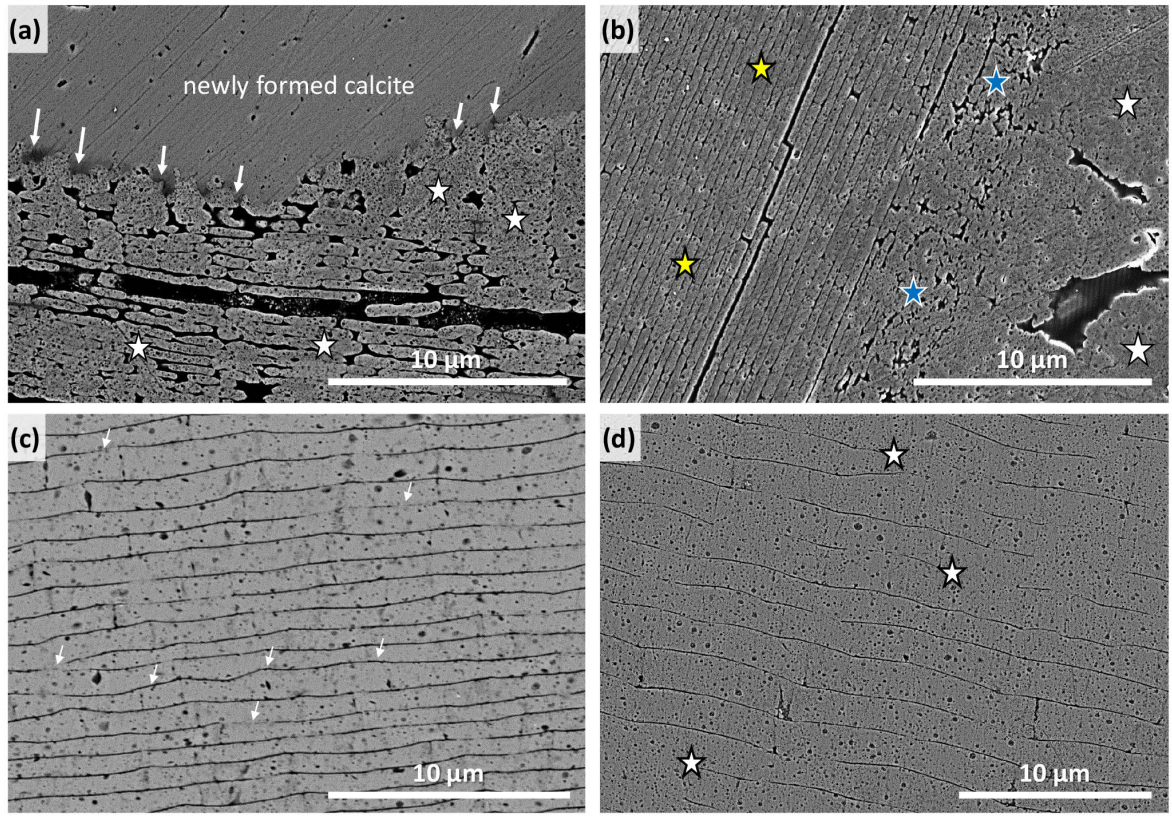

Figure A17. SEM images showing the distortion of the nacreous microstructure prior to phase replacement. (a, b) Haliotis ovina nacre, (c, d) Mytilus edulis nacre. White arrows in (a) point to high-Mg calcite "spots" at the replacement front between newly formed calcite and overprinted shell aragonite. White stars in (a) point to areas at the phase replacement front where traces of the original microstructure (tablets, columns) can be still observed. (b) Overprinted aragonite in three different microstructures: amalgamated nacre tablets (yellow star), over-worked, formerly tabular aragonite (blue stars), amalgamated aragonite prisms (white stars). (c, d) Mytilus edulis: strong tablet amalgamation (white stars in $\mathbf{d}$ ), tablet distortion (white arrows in c) and compaction of the nacreous microstructure. 
Author contributions. LAC, EG and WWS designed the study. VM, EMH, DJJ and AE provided sample material. LAC, VM, MG, SVV and SH performed the experiments. LAC, MG and SVV conducted the analyses and carried out the evaluation and merging of data. LAC, EG, LFD, UB and WWS drafted the manuscript. All authors contributed to discussions and the final manuscript.

Competing interests. The authors declare that they have no conflict of interest.

Acknowledgements. We thank the German Research Council (DFG) for financial support in the context of the collaborative research initiative CHARON (DFG Forschergruppe 1644, grant agreement no. SCHM 930/11-1). We acknowledge the helpful reviews by three anonymous reviewers and the editor Lennart de Nooijer, which considerably improved the quality of this paper.

Edited by: Lennart de Nooijer

Reviewed by: three anonymous referees

\section{References}

Addadi, L., Joester, D., Nudelman, F., and Weiner, S.: Mollusk shell formation: a source of new concepts for understanding biomineralization processes, Chemistry, 12, 980-987, 2006.

Allison, N., Finch, A. A., Webster, J. M., and Clague, D. A.: Palaeoenvironmental records from fossil corals: the effects of submarine diagenesis on temperature and climate estimates, Geochim. Cosmochim. Ac., 71, 4693-4703, 2007.

Altree-Williams, A., Pring, A., Ngothai, Y., and Brugger, J.: Textural and compositional complexities resulting from coupled dissolution-reprecipitation reactions in geomaterials, Earth-Sci. Rev., 150, 628-651, 2015.

Arvidson, R. S. and Morse, J. W.: Formation and diagenesis of carbonate sediments, in: Treatise on geochemistry, edited by: Holland H. D. and Turekian K. K., Elsevier, Oxford, 9, 61-101, 2014.

Barthelat, F. and Espinosa, H. D.: An experimental investigation of deformation and fracture of nacre-mother of pearl, Exp. Mech., 47, 311-324, 2007.

Bathurst, R. G. C.: Carbonate Sediments and their Diagenesis, Elsevier, Amsterdam, 1975.

Blanchon, P., Eisenhauer, A., Fietzke, J., and Liebetrau, V.: Rapid sea-level rise and reef back-stepping at the close of the last interglacial highstand, Nature, 458, 881-884, 2009.

Böhm, F., Gussone, N., Eisenhauer, A., Dullo, W.-C., Reynaud, S., and Paytan, A.: Calcium isotope fractionation in modern scleractinian corals, Geochim. Cosmochim. Ac., 70, 4452-4462, 2006.

Brand, U.: Aragonite-calcite transformation based on Pennsylvanian molluscs, Geol. Soc. Am. Bull., 101, 377-390, 1989.

Brand, U.: Morphochemical and replacement diagenesis of biogenic carbonates, Dev. Sedimentol., 51, 217-282, 1994.

Brand, U.: Carbon, oxygen and strontium isotopes in Paleozoic carbonate components: an evaluation of original seawater-chemistry proxies, Chem. Geol., 204, 23-44, 2004.
Brand, U. and Veizer, J.: Chemical diagenesis of a multicomponent carbonate-system - 1: trace elements, J. Sed. Petrol., 50, 12191236, 1980.

Brand, U. and Veizer, J.: Chemical diagenesis of a multicomponent carbonate system - 2: stable isotopes, J. Sed. Petrol., 51, $987-$ 997, 1981.

Brown, W. H., Fyfe, W. S., and Turner, F. J.: Aragonite in California glaucophane schists, and the kinetics of the aragonite-calcite transformation, J. Petrol., 3, 566-582, 1962.

Butler, P. G., Richardson, C. A., Scourse, J. D., Witbaard, R., Schöne, B. R., Fraser, N. M., Wanamaker Jr., A. D., Bryant, C. L., Harris, I., and Robertson, I.: Accurate increment identification and the spatial extent of the common signal in five Arctica islandica chronologies from the Fladen Ground, northern North Sea, Paleoceanography, 24, PA2210, https://doi.org/10.1029/2008PA001715, 2009.

Butler, P. G., Wanamaker Jr., A. D., Scourse, J. D., Richardson, C. A., and Reynolds, D. J.: Variability of marine climate on the North Icelandic Shelf in a 1,357-year proxy archive based on growth increments in the bivalve Arctica islandica, Palaeogeogr. Palaeocl., 373, 141-151, 2013.

Cardew, P. T. and Davey, R. J.: The kinetics of solvent-mediated phase transformations, P. Roy. Soc. Lond. A, 398, 415-428, 1985.

Cartwright, J. H. E. and Checa, A. G.: The dynamics of nacre selfassembly, J. R. Soc. Interface, 4, 491-504, 2007.

Casella, L. A., Griesshaber, E., Yin, X., Ziegler, A., Mavromatis, V., Müller, D., Ritter, A.-C., Hippler, D., Harper, E. M., Dietzel, M., Immenhauser, A., Schöne, B. R., Angiolini, L., and Schmahl, W. W.: Experimental diagenesis: insights into aragonite to calcite transformation of Arctica islandica shells by hydrothermal treatment, Biogeosciences, 14, 1461-1492, https://doi.org/10.5194/bg-14-1461-2017, 2017.

Casella, L. A., Griesshaber, E., Simonet Roda, M. d. M., Ziegler, A., Mavromatis, V., Henkel, D., Laudien, J., Häussermann, V., Neuser, R. D., Angiolini, L., Dietzel, M., Eisenhauer, A., Immenhauser, A., Brand, U., and Schmahl, W. W.: Micro- and nanostrucures reflect the degree of diagenetic alteration in modern and fossil brachiopod shell calcite: a multi-analytical screening approach (CL, FE-SEM, AFM, EBSD), Palaeogeogr. Palaeocl., 502, 13-30, 2018a.

Casella, L. A., Simonet Roda, M. D. M., Angiolini, L., Ziegler, A., Schmahl, W. W., Brand, U., and Griesshaber, E.: Archival biogenic micro- and nanostructure data analysis: signatures of diagenetic systems, Data In Brief, 19, 299-311, 2018 b.

Checa, A. G., Okamoto, T., and Ramírez, J.: Organization pattern of nacre in Pteriidae (Bivalvia: Mollusca) explained by crystal competition, Proc. Biol. Sci., 273, 1329-1337, 2006.

Checa, A. G., Cartwright, J. H. E., and Willinger, M.-G.: The key role of the surface membrane in why gastropod nacre grows in towers, P. Natl. Am. Soc., 106, 38-43, 2009.

Checa, A. G., Cartwright, J. H. E., and Willinger, M.-G.: Mineral bridges in nacre, J. Struct. Biol., 176, 330-339, 2011.

Checa, A. G., Pina, C. M., Osuna-Mascaró, A. J., RodríguesNavarro, A. B., and Harper, E. M.: Crystalline organization of the fibrous prismatic calcitic layer of the Mediterranean mussel Mytilus galloprovincialis, Eur. J. Mineral., 26, 495-505, 2014. 
Cherns, L., Wheeley, J. R., and Wright, V. P.: Taphonomic windows and molluscan preservation, Palaeogeogr. Palaeocl., 270, 220229, 2008.

Cohen, A. L., Layne, G. D., and Hart, S. R.: Kinetic control of skeletal $\mathrm{Sr} / \mathrm{Ca}$ in a symbiotic coral: implications for the paleotemperature proxy, Paleoceanography, 16, 20-26, 2001.

Crippa, G. and Raineri, G.: The genera Glycymeris, Aequipecten and Arctica, and associated mollusk fauna of the Lower Pleistocene Arda River section (Northern Italy), Riv. Ital. Paleontol. Stratigr., 121, 61-101, 2015.

Crippa, G., Angiolini, L., Bottini, C., Erba, E., Felletti, F. Frigerio, C., Hennissen, J. A., Leng, M. J., Petrizzo, M. R., Raffi, I., Raineri, G., and Stephenson, M. H.: Seasonality fluctuations recorded in fossil bivalves during the early Pleistocene: implications for climate change, Palaeogeogr. Palaeocl., 446, 234-251, 2016.

Cuesta Mayorga, I., Astilleros, J. M., Fernández-Díaz, L., Morales, J., Prieto, M., Roncal-Herrero, T., and Benning, L. G.: Epitactic overgrowths of calcite $\left(\mathrm{CaCO}_{3}\right)$ on anhydrite $\left(\mathrm{CaSO}_{4}\right)$ cleavage surfaces, Cryst. Growth Des., 18, 1666-1675, 2018.

Delanghe, D., Bard, E., and Hamelin, B.: New TIMS constraints on the uranium-238 and uranium-234 in seawaters from the main ocean basins and the Mediterranean Sea, Mar. Chem., 80, 79-93, 2002.

Elliot, M., deMenocalm, P. B., Linsley, B. K., and Howe, S. S.: Environmental controls on the stable isotopic composition of Mercenaria mercenaria: potential application to paleoenvironmental studies, Geochem. Geophys. Geosyst., 4, 1056, https://doi.org/10.1029/2002GC000425, 2003.

Etschmann, B., Brugger, J., Pearce, M. A., Ta, C., Brautigan, D., Jung, M., and Pring, A.: Grain boundaries as microreactors during reactive fluid flow: experimental dolomitization of a calcite marble, Contrib. Mineral. Petrol., 168, 1045, https://doi.org/10.1007/s00410-014-1045-z, 2014.

Fabritius, H., Walther, P., and Ziegler, A.: Architecture of the organic matrix in the sternal $\mathrm{CaCO}_{3}$ deposits of Porcellio scaber (Crustacea, Isopoda), J. Struct. Biol., 150, 190-199, 2005.

Fernández-Díaz, L., Pina, C. M., Astilleros, J. M., and SánchezPastor, N.: The carbonatation of gypsum: pathways and pseudomorph formation, Am. Mineral., 94, 1223-1234, 2009.

Friedman, G. M.: Early diagenesis and lithification in carbonate sediments, J. Sediment. Petrol., 34, 777-813, 1964.

Greiner, M., Férnandez-Díaz, L., Griesshaber, E., Zenkert, M. N., Yin, X., Ziegler, A., Veintemillas-Verdaguer, S., and Schmahl, W. W.: Biomineral reactivity: the kinetics of the replacement reaction of biological aragonite to apatite, Minerals, 8, 315, https://doi.org/10.3390/min8080315, 2018.

Gries, K., Kroger, R., Kubel, C., Schowalter, M., Fritz, M., and Rosenauer, A.: Correlation of the orientation of stacked aragonite platelets in nacre and their connection via mineral bridges, Ultramicroscopy, 109, 230-236, 2009.

Griesshaber, E., Schmahl, W. W., Ubhi, H. S., Huber, J., Nindiyasari, F., Maier, B., and Ziegler, A.: Homoepitaxial mesoand microscale crystal co-orientation and organic matrix network structure in Mytilus edulis nacre and calcite, Acta Biomater., 9, 9492-9502, 2013.

Griesshaber, E., Yin, X., Ziegler, A., Kelm, K., Checa, A., Eisenhauer, A., and Schmahl, W. W.: Patterns of mineral organization in carbonate biological hard materials, in: Highlights in Applied
Mineralogy, edited by: Heuss-Aßbichler, S., Amthauer, G., and John, M., de Gruyter, Berlin, 2017.

Hahn, S., Rodolfo-Metalpa, R., Griesshaber, E., Schmahl, W. W., Buhl, D., Hall-Spencer, J. M., Baggini, C., Fehr, K. T., and Immenhauser, A.: Marine bivalve shell geochemistry and ultrastructure from modern low $\mathrm{pH}$ environments: environmental effect versus experimental bias, Biogeosciences, 9, 1897-1914, https://doi.org/10.5194/bg-9-1897-2012, 2012.

Hahn, S., Griesshaber, E., Schmahl, W. W., Neuser, R. D., Ritter, A.-C., Hoffmann, R., Buhl, D., Niedermayr, A., Geske, A., and Immenhauser, A.: Exploring aberrant bivalve shell ultrastructure and geochemistry as proxies for past sea water acidification, Sedimentology, 61, 1625-1658, 2014.

Hamelin, B., Bard, E., Zindler, A., and Fairbanks, R. G.: ${ }^{234} \mathrm{U} /{ }^{238} \mathrm{U}$ mass spectrometry of corals: how accurate is the U-Th age of the last interglacial period?, Earth Planet. Sc. Lett., 106, 169-180, 1991.

Harper, E. M.: The fossil record of bivalve molluscs, in: The adequacy of the fossil record, edited by: Donovan S. K. and Paul C. R. C., John Wiley and Sons, Chichester, 243-267, 1998.

Heiss, G. A.: Coral reefs in the Red Sea: growth, production, and stable isotopes, Geomar. Report, 32, 1-141, 1994.

Henderson, G. M., Cohen, A. S., and O’Nions, R. K.: ${ }^{234} \mathrm{U} /{ }^{238} \mathrm{U}$ ratios and ${ }^{230} \mathrm{Th}$ ages for Hateruma Atoll corals: implications for coral diagenesis and seawater ${ }^{234} \mathrm{U} /{ }^{238} \mathrm{U}$ ratios, Earth Planet. Sc. Lett., 115, 65-73, 1993.

Hendry, J. P., Dirchfield, P. W., and Marshall, J. D.: Two-stage neomorphism of Jurassic aragonitic bivalves: implications for early diagenesis, J. Sediment. Res., A65, 214-224, 1995.

Hippler, D., Buhl, D., Witbaard, R., and Immenhauser, A.: Towards a better understanding of magnesium-isotope ratios, Geochim. Cosmochim. Ac., 73, 6134-6146, 2009.

Hover, V. C., Walter, L. M., and Peacor, D. R.: Early marine diagenesis of biogenic aragonite and $\mathrm{Mg}$-calcite: new constraints from high-resolution STEM and AEM analyses of modern platform carbonates, Chem. Geol., 175, 221-248, 2001.

Immenhauser, A., Schöne, B. R., Hoffmann, R., and Niedermayr, A.: Mollusc and brachiopod skeletal hard parts: intricate archives of their marine environment, Sedimentology, 63, 1-59, 2015.

Jackson, A. P., Vincent, J. F. V., and Turner, R. M.: The mechanical design of nacre, P. Roy. Soc. B, 234, 415-440, 1988.

James, N. P., Bone, Y., and Kyser, K. T.: Where has all the aragonite gone? Mineralogy of Holocene neritic cool-water carbonates, Southern Australia, J. Sediment. Res., 75, 454-463, 2005.

Jarosch, D. and Heger, G.: Neutron diffraction refinement of the crystal structure of aragonite, Tscher. Miner. Petrog., 35, 127$131,1986$.

Jonas, L., John, T., King, H. E., Geisler, T., and Putnis, A.: The role of grain boundaries and transient porosity in rocks as fluid pathways for reaction front propagation, Earth Planet. Sc. Lett., 386, 64-74, 2014.

Jonas, L., Müller, T., Dohmen, R., Baumgartner, L., and Putlitz, B.: Transport-controlled hydrothermal replacement of calcite by Mg-carbonates, Geology, 43, 779-782, 2015.

Karney, G. B., Butler, P. G., Speller, S., Scourse, J. D., Richardson, C. A., Schröder, M., Highes, G. M., Czernuszka, J. T., and Grovenor, C. R. M.: Characterizing the microstructure of Arctica islandica shells using NanoSIMS and EBSD, Geochem. Geophys. Geosyst., 13, 1-14, 2012. 
Kidwell, S. M.: Shell composition has no net impact on large-scale evolutionary patterns in mollusks, Science, 307, 914-917, 2005.

Korte, C., Kozur, H. W., and Veizer, J.: $\delta^{13} \mathrm{C}$ and $\delta^{18} \mathrm{O}$ values of Triassic brachiopods and carbonate rocks as proxies for coeval seawater and palaeotemperature, Palaeogeogr. Palaeocl., 226, 287306, 2005 .

Krause-Nehring, J., Brey, T., and Thorrold, S. R.: Centennial records of lead contamination in northern Atlantic bivalves (Arctica islandica), Mar. Pollut. Bull., 64, 233-240, 2012.

Ku, T. C. W., Walter, L. M., Coleman, M. L., Blake, R. E., and Martini, A. M.: Coupling between sulfur recycling and syndepositional carbonate dissolution: evidence from oxygen and sulfur isotope composition of pore water sulfate, South Florida Platform, U. S. A., Geochim. Cosmochim. Ac., 63, 2529-2546, 1999.

Land, L. S.: Diagenesis of skeletal carbonates, J. Sediment. Res., 37, 914-930, 1967.

Levi-Kalisman, Y., Falini, G., Addadi, L., and Weiner, S.: Structure of the nacreous organic matrix of a bivalve mollusk shell examined in the hydrated state using Cryo-TEM, J. Struct. Biol., 135, 8-17, 2001.

Li, X., Xu, Z.-H., and Wang, R.: In situ observation of nanograin rotation and deformation in nacre, Nano Lett., 6, 2301-2304, 2006.

Maliva, R. G., Missimer, T. M., and Dickson, J. A. D.: Skeletal aragonite neomorphism in Plio-Pleistocene sandy limestones and sandstones, Holloywood, Florida, U.S.A., Sediment. Geol., 136, 147-154, 2000.

Marchitto, T. M., Jones, G. A., Goodfriend, G. A., and Weidman, C. R.: Precise temporal correlation of Holocene mollusk shells using sclerochronology, Quat. Res., 53, 236-246, 2000.

Marin, F. and Luquet, G.: Molluscan shell proteins, C. R. Palevol., 3, 469-492, 2004.

Markgraf, S. A. and Reeder, R. J.: High-temperature structure refinements of calcite and magnesite, Am. Mineral., 70, 590-600, 1985.

Martin, G. D., Wilkinson, B. H., and Lohmann, K. C.: The role of skeletal porosity in aragonite neomorphism - Strombus and Montastrea from the Pleistocene Key Largo Limestone, Florida, J. Sediment. Petrol., 56, 194-203, 1986.

Mayer, G.: Rigid biological systems as models for synthetic composites, Science, 298, 1144-1147, 2005.

McGregor, H. V. and Gagan, M. K.: Diagenesis and geochemistry of Porites corals from Papua New Guinea: implications for paleoclimate reconstruction, Geochim. Cosmochim. Ac., 67, 21472156, 2002.

Meibom, A., Mostefaoui, S., Cuif, J.-P., Dauphin, Y., Houlbreque, F., Dunbar, R., and Constantz, B.: Biological forcing controls the chemistry of reef-building coral skeleton, Geophys. Res. Lett., 34, L02601, https://doi.org/10.1029/2006GL028657, 2007.

Metzler, R. A., Abrecht, M., Olabisi, R. M., Ariosa, D., Johnson, C. J., Frazer, B. H., Coppersmith, S. N., and Gilbert, P. U. P. A.: Architecture of columnar nacre, and implications for its formation mechanism, Phys. Rev. Lett., 98, 268102, https://doi.org/10.1103/PhysRevLett.98.268102, 2007.

Morton, B.: The biology and functional morphology of Arctica islandica (Bivalvia: Arcticidae): a gerontophilic living fossil, Mar. Biol. Res., 7, 540-553, 2011.

Nindiyasari, F., Ziegler, A., Griesshaber, E., Fernández-Díaz, L., Huber, J., Walther, P., and Schmahl, W. W.: Effect of hydrogel matrices on calcite crystal growth morphology, aggregate formation, and co-orientation in biomimetic experiments and biomineralization environments, Cryst. Growth Des., 15, 2667-2685, 2015.

Patterson, W. P. and Walter, L. M.: Sydepositional diagenesis of modern platform carbonates: evidence from isotopic and minor element data, Geology, 22, 127-130, 1994.

Perdikouri, C., Kasioptas, A., Geisler, T., Schmidt, B. C., and Putnis, A.: Experimental study of the aragonite to calcite transition in aqueous solution, Geochim. Cosmochim. Ac., 75, 6211-6224, 2011.

Perdikouri, C., Piazolo, S., Kasioptas, A., Schmidt, B. C., and Putnis, A.: Hydrothermal replacement of aragonite by calcite: interplay between replacement, fracturing and growth, Eur. J. Mineral., 25, 123-136, 2013.

Pollok, K., Putnis, C. V., and Putnis, A.: Mineral replacement reactions in solid solution-aqueous solution systems: volume changes, reactions paths and end-points using the example of model salt systems, Am. J. Sci., 311, 211-236, 2011.

Putnis, A.: Mineral replacement reactions: from macroscopic observations to microscopic mechanisms, Mineral. Mag., 66, 689708, 2002.

Putnis, A.: Mineral replacement reactions, Rev. Mineral. Geochem., 70, 87-124, 2009

Qian, G., Brugger, J., Skinner, W. M., Chen, G., and Pring, A.: An experimental study of the mechanism of the replacement of magnetite by pyrite up to $300^{\circ} \mathrm{C}$, Geochim. Cosmochim. Ac., 74, 5610-5630, 2010.

Raffi, S.: The significance of marine boreal molluscs in the Early Pleistocene faunas of the Mediterranean area, Palaeogeogr. Palaeocl., 52, 267-289, 1986.

Randle, V. and Engler, O.: Introduction to texture analysis, CRC Press, Amsterdam, 2000.

Rashid, R., Eisenhauer, A., Stocchi, P., Fietzke, J., Rüggeberg, A., and Dullo, W.-C.: Constraining mid to late Holocene relative sea level change in the southern equatorial Pacific Ocean relative to the Society Islands, French Polynesia, Geochem. Geophy. Geosy., 15, 2601-2615, 2014.

Regenberg, M., Nürnberg, D., Schönfeld, J., and Reichart, G.-J.: Early diagenetic overprint in Caribbean sediment cores and its effect on the geochemical composition of planktonic foraminifera, Biogeosciences, 4, 957-973, https://doi.org/10.5194/bg-4-9572007, 2007.

Richardson, C. A.: Molluscs as archives of environmental change, Oceanogr. Mar. Biol., 39, 103-164, 2001.

Ridgway, I. D., Richardson, C. A., and Austad, S. N.: Maximum shell size, growth rate, and maturation age correlate with longevity in bivalve molluscs, J. Gerontol. A Biol. Sci. Med. Sci., 66, 183-190, 2011.

Ritter, A.-C., Mavromatis, V., Dietzel, M., Wiethoff, F., Griesshaber, E., Casella, L. A., Schmahl, W. W., Koelen, J., Neuser, R. D., Leis, A., Buhl, D., Niedermayr, A., Bernasconi, S. M., and Immenhauser, A.: Exploring the impact of diagenesis on (isotope)geochemical and microstructural alteration features in biogenic aragonite, Sedimentology, 64, 1354-1380, 2017.

Rodríguez-Carvajal, J.: Recent developments of the program FULLPROF, Commission on Powder Diffraction (IUCr), Newsletter, 26, 12-19, 2001. 
Roncal-Herrero, T., Astilleros, J. M., Bots, P., Diego, J., Blanco, R., Prieto, M., Benning, L. G., and Fernández-Díaz, L.: Reaction pathways and textural aspects of the replacement of anhydrite by calcite at $25^{\circ} \mathrm{C}, \mathrm{Am}$. Mineral., 120, 1270-1278, 2017.

Rüggeberg, A., Fietzke, J., Liebetrau, V., Eisenhauer, A., Dullo, W.-C., and Freiwald, A.: Stable strontium isotopes $\left(\delta^{88 / 86} \mathrm{Sr}\right)$ in cold-water corals - a new proxy for reconstruction of intermediate ocean water temperatures, Earth Planet. Sc. Lett., 269, 570-575, 2008.

Ruíz-Agudo, E., Putnis, C. V., and Putnis, A.: Coupled dissolution and precipitation at mineral-fluid interfaces, Chem. Geol., 383, 132-146, 2014.

Sandberg, P. A. and Hudson, J. D.: Aragonite relic preservation in Jurassic calcite-replaced bivalves, Sedimentology, 30, 879-892, 1983.

Schmahl, W. W., Griesshaber, E., Kelm, K., Goetz, A., Jordan, G., Ball, A., Xu, D., Merkel, C., and Brand, U.: Hierarchical structure of marine shell biomaterials: biomechanical functionalization of calcite by brachiopods, Z. Kristallogr., 227, 793-804, 2012.

Schmidt, N. H. and Olesen, N. O.: Computer-aided determination of crystal-lattice orientation from electron channeling patterns in the SEM, Can. Mineral., 27, 15-22, 1989.

Schöne, B. R.: Arctica islandica (Bivalvia): a unique paleoenvironmental archive of the northern North Atlantic Ocean, Global Planet. Change, 111, 199-225, 2013.

Schöne, B. R. and Surge, D. M.: Bivalve sclerochronology and geochemistry, in: Treatise on invertebrate Paleontology (Part N Revised), edited by: Selden, P. A., Treatise Online, 46, 1-24, 2012.

Schöne, B. R., Freyre Castro, A. D., Fiebig, J., Houk, S. D., Oschmann, W., and Kröncke, I.: Sea surface water temperatures over the period 1884-1983 reconstructed from oxygen isotope ratios of a bivalve mollusk shell (Arctica islandica, southern North Sea), Palaeogeogr. Palaeocl., 212, 215-232, 2004.

Schöne, B. R., Houk, S. D., Freyre Castro, A. D., Fiebig, J., Kröncke, I., Dreyer, W., Gosselck, F., and Oschmann, W.: Daily growth rates in shells of Arctica islandica: assessing subseasonal environmental controls on a long-lived bivalve mollusc, Palaios, 20, 78-92, 2005a.

Schöne, B. R., Pfeiffer, M., Pohlmann, T., and Siegismund, F.: A seasonally resolved bottom-water temperature record for the period as 1866-2002 based on shells of Arctica islandica (Mollusca, North Sea), Int. J. Climatol., 25, 947-962, 2005 b.

Sorauf, J. E.: Biomineralization, structure and diagenesis of the coelenterate skeleton, Acta Palaeont. Polonica, 25, 237-343, 1980.

Stirling, C. H., Esat, T. M., McCulloch, M. T., and Lambeck, K.: High-precision U-series of corals from Western Australia and implications for the timing and duration of the Last Interglacial, Earth Planet. Sc. Lett., 135, 115-130, 1995.
Strahl, J., Dringen, R., Schmidt, M. M., Hardenberg, S., and Abele, D.: Metabolic and physiological responses in tissues of the longlived bivalve Arctica islandica to oxygen deficiency, Comp. Biochem. Physiol. A, 158, 513-519, 2011.

Swart, P. K.: The geochemistry of carbonate diagenesis: the past, present and future, Sedimentology, 62, 1233-1304, 2015.

Tomiak, P. J., Andersen, M. B., Hendy, E. J., Potter, E. K., Johnson, K. G., and Penkman, K. E. H.: The role of skeletal microarchitecture in diagenesis and dating of Acropora palmata, Geochim. Cosmochim. Ac., 183, 153-175, 2016.

Ullmann, C. V. and Korte, C.: Diagenetic alteration in low-Mg calcite from macrofossils: a review, Geol. Quart., 59, 3-20, 2015.

Wanamaker Jr., A. D., Kreutz, K. J., Schöne, B. R., Pettigrew, N., Borns, H. W., Introne, D. S., Belknap, D., Maasch, K. A., and Feindel, S.: Coupled North Atlantic slope water forcing on Gulf of Maine temperatures over the past millennium, Clim. Dynam., 31, 183-194, 2008.

Wanamaker Jr., A. D., Kreutz, K. J., Schöne, B. R., and Introne, D. S.: Gulf of Main shells reveal changes in seawater temperature seasonality during the Medieval Climate Anomaly and the Little Ice Age, Palaeogeogr. Palaeocl., 302, 43-51, 2011.

Wardlaw, N., Oldershaw, A., and Stout, M.: Transformation of aragonite to calcite in a marine gastropod, Can. J. Earth Sci., 15, 1861-1866, 1978.

Wright, V. P., Cherns, L., and Hodges, P.: Missing molluscs: field testing taphonomic loss in the Mesozoic through early largescale aragonite dissolution, Geology, 31, 211-214, 2003.

Xia, F., Brugger, J. I., Chen, G., Ngothai, Y., O’Neill, B., Putnis, A., and Pring, A.: Mechanism and kinetics of pseudomorphic mineral replacement reactions: a case study of the replacement of pentlandite by violarite, Geochim. Cosmochim. Ac. 73, 19451969, 2009a.

Xia, F., Brugger, J. I., Ngothai, Y., O’Neill, B., Chen, G., and Pring, A.: Three-dimensional ordered arrays of zeolite nanocrystals with uniform size and orientation by a pseudomorphic coupled dissolution-reprecipitation replacement route, Cryst. Growth Des., 9, 4902-4906, 2009b.

Zazzo, A., Lécuyer, C., Sheppard, S. M., Grandjean, P., and Mariotti, A.: Diagenesis and the reconstruction of paleoenvironments: a method to restore original $\delta^{18} \mathrm{O}$ values of carbonate and phosphate from fossil tooth enamel, Geochim. Cosmochim. Ac., 68, 2245-2258, 2004. 